\title{
Expedient Synthesis of Chiral 1,2- and 1,4-Diamines: Protecting Group Dependent Regioselectivity in Direct Organocatalytic Asymmetric Mannich Reactions
}

\author{
Naidu S. Chowdari, Moballigh Ahmad, Klaus Albertshofer, Fujie Tanaka, \\ and Carlos F. Barbas III* \\ Contribution from The Skaggs Institute for Chemical Biology and the Departments of Chemistry and Molecular \\ Biology, The Scripps Research Institute, 10550 North Torrey Pines Road, La Jolla, California
}

\section{Supporting Information}

General. Chemicals and solvents were either purchased puriss p.A. from commercial suppliers or purified by standard techniques. For thin-layer chromatography (TLC), silica gel plates Merck 60 F254 were used and compounds were visualized by irradiation with UV light and/or by treatment with a solution of $p$-anisaldehyde $(23 \mathrm{~mL})$, conc. $\mathrm{H}_{2} \mathrm{SO}_{4}(35 \mathrm{~mL})$, acetic acid (10 $\mathrm{mL})$, and ethanol $(900 \mathrm{~mL})$ followed by heating. Flash chromatography was performed using silica gel Merck 60 (particle size 0.040-0.063 mm), ${ }^{1} \mathrm{H}$ NMR and ${ }^{13} \mathrm{C}$ NMR spectra were recorded on Bruker DRX-400, DRX-500 MHz. Chemical shifts are given in $\delta$ relative to tetramethylsilane (TMS), the coupling constants $J$ are given in Hz. The spectra were recorded in $\mathrm{CDCl}_{3}$ as solvent at room temperature, TMS served as internal standard $(\delta=0 \mathrm{ppm})$ for ${ }^{1} \mathrm{H}$ NMR, and $\mathrm{CDCl}_{3}$ was used as internal standard $(\delta=77.0 \mathrm{ppm})$ for ${ }^{13} \mathrm{C}$ NMR. HPLC was carried out using a Hitachi organizer consisting of a D-2500 Chromato-Integrator, a L-4000 UVDetector, and a L-6200A Intelligent Pump. Optical rotations were recorded on a Perkin Elemer 241 Polarimeter $(\lambda=589 \mathrm{~nm}, 1 \mathrm{dm}$ cell). High-resolution mass spectra were recorded on an IonSpec FTMS mass spectrometer with a DHB-matrix.

General experimental procedure for two-component Mannich reaction (Table 1): To a glass vial charged with imine $(0.5 \mathrm{mmol})$ in solvent $(1 \mathrm{~mL})$ was added ketone $(0.75 \mathrm{mmol})$ followed by catalyst $(30 \mathrm{~mol} \%)$ and the reaction was stirred until completion as monitored by TLC. Then, a half saturated $\mathrm{NH}_{4} \mathrm{Cl}$ solution and ethyl acetate were added with vigorous stirring, 
the layers were separated and the organic phase was washed with water. The combined organic phases were dried $\left(\mathrm{Na}_{2} \mathrm{SO}_{4}\right)$, concentrated, and purified by flash column chromatography (silica gel, mixtures of hexanes/ethyl acetate) to afford the desired Mannich product.

General experimental procedure for three-component Mannich reaction (Table 2 \& 3): To a glass vial charged with aldehyde $(0.5 \mathrm{mmol})$ and $p$-anisidine $(0.5 \mathrm{mmol})$ was added DMSO (1 $\mathrm{mL}$ ) and stirred at room temperature until imine formation is complete as monitored by TLC (30-60 min). Then catalyst $(30 \mathrm{~mol} \%)$ followed by ketone $(0.75 \mathrm{mmol})$ was added and the reaction was stirred at room temperature. After completion of the reaction as monitored by TLC, half saturated $\mathrm{NH}_{4} \mathrm{Cl}$ solution and ethyl acetate were added under vigorous stirring, the layers were separated and the organic phase was washed with water. The combined organic phases were dried $\left(\mathrm{Na}_{2} \mathrm{SO}_{4}\right)$, concentrated, and purified by flash column chromatography (silica gel, mixtures of hexanes/ethyl acetate) to afford the desired Mannich product.

\section{(2S,3S)-ethyl-3-azido-2-(4-methoxyphenylamino)-4-oxohexanoate (4):}

To a glass vial charged with $\alpha$-imino ethyl glyoxylate $(104 \mathrm{mg}, 0.5$ mmol) in DMSO $(1 \mathrm{~mL})$ was added azidobutanone $(0.75 \mathrm{mmol})$ followed by catalyst $3(30 \mathrm{~mol} \%)$ and stirred at room temperature for $4 \mathrm{~h}$ as monitored by TLC. Then, a half saturated $\mathrm{NH}_{4} \mathrm{Cl}$ solution and ethyl

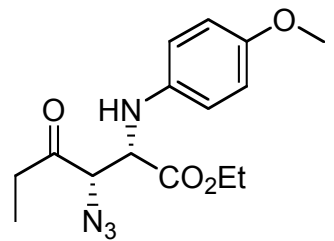
acetate were added with vigorous stirring, the layers were separated and the organic phase was washed with water. The combined organic phases were dried $\left(\mathrm{Na}_{2} \mathrm{SO}_{4}\right)$, concentrated, and purified by flash column chromatography (silica gel, mixtures of hexanes/ethyl acetate) to afford the desired Mannich product. ${ }^{1} \mathrm{H}$ NMR $\left(\mathrm{CDCl}_{3}, 400 \mathrm{MHz}\right): \delta 1.06(\mathrm{t}, 3 \mathrm{H}), 1.26(\mathrm{t}, 3 \mathrm{H}, J=7.2$ $\mathrm{Hz}), 2.64\left(\mathrm{dq}, 2 \mathrm{H}, J_{1}=1.6 \mathrm{~Hz}, J_{2}=7.2 \mathrm{~Hz}\right), 3.73(\mathrm{~s}, 3 \mathrm{H}), 4.22(\mathrm{~m}, 2 \mathrm{H}), 4.49(\mathrm{~d}, 1 \mathrm{H}, J=3.2 \mathrm{~Hz})$, $4.52(\mathrm{~m}, 1 \mathrm{H}), 6.63(\mathrm{~d}, J=8.8 \mathrm{~Hz}, 2 \mathrm{H}), 6.76(\mathrm{~d}, J=8.8 \mathrm{~Hz}, 2 \mathrm{H}) ;{ }^{13} \mathrm{C} \mathrm{NMR}\left(\mathrm{CDCl}_{3}, 100 \mathrm{MHz}\right): \delta$ $7.07,7.22,33.53,55.52,60.07,61.99,62.08,70.12,70.16,114.65,114.80,116.37,116.54$, 116.58, 140.05, 153.62, 170.69, 206,02; HRMS for $\mathrm{C}_{15} \mathrm{H}_{20} \mathrm{~N}_{4} \mathrm{O}_{4}\left(\mathrm{MH}^{+}\right)$: calcd 321.1557, obsd 321.1553; HPLC (Daicel Chiralcel OJ-H, hexane/isopropanol $=85: 15$, flow rate $1.0 \mathrm{~mL} / \mathrm{min}, \lambda$ $=254 \mathrm{~nm}): \mathrm{t}_{\mathrm{R}}=22.90 \min ($ syn, major $), \mathrm{t}_{\mathrm{R}}=27.82 \min ($ syn, minor $), \mathrm{t}_{\mathrm{R}}=43.23 \min ($ anti, major), $\mathrm{t}_{\mathrm{R}}=76.30 \min$ (anti, minor). 


\section{(2S,3S)-ethyl-3-azido-2-(4-methoxyphenylamino)-4-oxopentanoate}

(5): To a glass vial charged with $\alpha$-imino ethyl glyoxylate $(104 \mathrm{mg}, 0.5$ $\mathrm{mmol})$ in DMSO $(1 \mathrm{~mL})$ was added azidoacetone $(0.75 \mathrm{mmol})$ followed by catalyst 3 (30 $\mathrm{mol} \%)$ and stirred at room temperature for $30 \mathrm{~min}$ as monitored by TLC. Then, a half saturated $\mathrm{NH}_{4} \mathrm{Cl}$ solution and ethyl

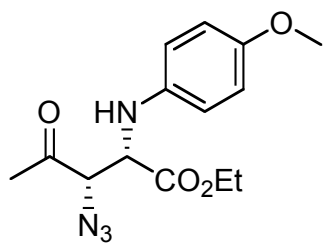
acetate were added with vigorous stirring, the layers were separated and the organic phase was washed with water. The combined organic phases were dried $\left(\mathrm{Na}_{2} \mathrm{SO}_{4}\right)$, concentrated, and purified by flash column chromatography (silica gel, mixtures of hexanes/ethyl acetate) to afford the desired Mannich product. ${ }^{1} \mathrm{H}$ NMR $\left(\mathrm{CDCl}_{3}, 400 \mathrm{MHz}\right): \delta 1.27$ (t, $\left.J=7.2 \mathrm{~Hz}, 3 \mathrm{H}\right), 2.31$ (s, $3 \mathrm{H}), 3.73(\mathrm{~s}, 3 \mathrm{H}), 4.04(\mathrm{~d}, 1 \mathrm{H}, J=6.0 \mathrm{~Hz}), 4.22(\mathrm{~m}, 2 \mathrm{H}), 4.51(\mathrm{~m}, 2 \mathrm{H}), 6.44(\mathrm{~d}, J=8.8 \mathrm{~Hz}$, $2 \mathrm{H}), 6.76(\mathrm{~d}, J=8.8 \mathrm{~Hz}, 2 \mathrm{H}) ;{ }^{13} \mathrm{C} \mathrm{NMR}\left(\mathrm{CDCl}_{3}, 100 \mathrm{MHz}\right): \delta 14.11,27.66,55.52,55.67,59.94$, $62.11,70.33,70.38,114.67,114.81,116.38,116.53,138.80,139.99,153.66,170.53,203.31$; HRMS for $\mathrm{C}_{14} \mathrm{H}_{18} \mathrm{~N}_{4} \mathrm{O}_{4}\left(\mathrm{MNa}^{+}\right)$: calcd 329.122, obsd 329.1224; HPLC (Daicel Chirapak AD, hexane/isopropanol $=97: 3$, flow rate $1.0 \mathrm{~mL} / \mathrm{min}, \lambda=254 \mathrm{~nm}$ ): $\mathrm{t}_{\mathrm{R}}=20.47 \mathrm{~min}$ (syn, minor), $\mathrm{t}_{\mathrm{R}}$ $=22.07 \min \left(\right.$ syn, major), $\mathrm{t}_{\mathrm{R}}=24.44 \min$ (anti, minor), $\mathrm{t}_{\mathrm{R}}=26.27 \min$ (anti, major).

\section{(2S,3S)-ethyl-3-azido-2-(4-methoxyphenylamino)-4-oxo-4-}

phenylbutanoate (6): To a glass vial charged with $\alpha$-imino ethyl glyoxylate (104 mg, $0.5 \mathrm{mmol})$ in DMSO $(1 \mathrm{~mL})$ was added azidoacetophenone $(0.75 \mathrm{mmol})$ followed by catalyst 3 (30 mol\%) and stirred at room temperature for $40 \mathrm{~h}$ as monitored by TLC. Then,

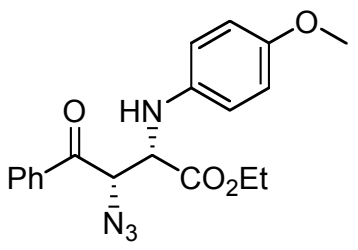
a half saturated $\mathrm{NH}_{4} \mathrm{Cl}$ solution and ethyl acetate were added with vigorous stirring, the layers were separated and the organic phase was washed with water. The combined organic phases were dried $\left(\mathrm{Na}_{2} \mathrm{SO}_{4}\right)$, concentrated, and purified by flash column chromatography (silica gel, mixtures of hexanes/ethyl acetate) to afford the desired Mannich product. ${ }^{1} \mathrm{H}$ NMR $\left(\mathrm{CDCl}_{3}, 400\right.$ MHz): $\delta 1.20$ (t, 3H, J = 7.2 Hz), 3.75 (s, 3H), $4.15(\mathrm{~m}, 2 \mathrm{H}), 4.26(\mathrm{~m}, 1 \mathrm{H}), 4.59(\mathrm{~m}, 1 \mathrm{H}), 4.97$ $(\mathrm{d}, J=7.2 \mathrm{~Hz}, 1 \mathrm{H}), 6.73(\mathrm{~d}, J=9.2 \mathrm{~Hz}, 2 \mathrm{H}), 6.80(\mathrm{~d}, J=9.2 \mathrm{~Hz}, 2 \mathrm{H}), 7.52(\mathrm{~m}, 2 \mathrm{H}), 7.63(\mathrm{~m}, 1$ $\mathrm{H}), 7.96(\mathrm{~m}, 2 \mathrm{H}) ;{ }^{13} \mathrm{C} \mathrm{NMR}\left(\mathrm{CDCl}_{3}, 100 \mathrm{MHz}\right): \delta 13.92,55.59,55.63,60.64,61.95,64.05$, 
114.86, 116.74, 128.63, 128.94, 134.06, 135.26, 139.69, 153.69, 170.41, 194.93; HRMS for $\mathrm{C}_{19} \mathrm{H}_{20} \mathrm{~N}_{4} \mathrm{O}_{4}\left(\mathrm{MH}^{+}\right)$: calcd 369.1557, obsd 369.1556; ee was determined by HPLC analysis of $\mathbf{1 0}$.

\section{(3S,4S)-3-azido-5-(benzyloxy)-4-(4-methoxyphenylamino)pentan-2-}

one (7): To a glass vial charged with benzyloxyacetaldehyde $(0.5 \mathrm{mmol})$ and $p$-anisidine $(0.5 \mathrm{mmol})$ was added DMSO $(1 \mathrm{~mL})$ and stirred at room temperature until imine formation is complete as monitored by TLC (30 $\mathrm{min})$. Then catalyst 3 (30 mol\%) followed by azidoacetone $(0.75 \mathrm{mmol})$

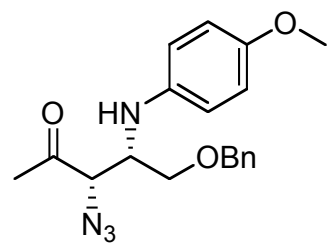
was added and the reaction was stirred at room temperature for $30 \mathrm{~min}$. Then, half saturated $\mathrm{NH}_{4} \mathrm{Cl}$ solution and ethyl acetate were added under vigorous stirring, the layers were separated and the organic phase was washed with water. The combined organic phases were dried $\left(\mathrm{Na}_{2} \mathrm{SO}_{4}\right)$, concentrated, and purified by flash column chromatography (silica gel, mixtures of hexanes/ethyl acetate) to afford the desired Mannich product. ${ }^{1} \mathrm{H} \mathrm{NMR}\left(\mathrm{CDCl}_{3}, 400 \mathrm{MHz}\right): \delta$ $2.18(\mathrm{~s}, 3 \mathrm{H}), 3.46(\mathrm{t}, J=8.8 \mathrm{~Hz}, 1 \mathrm{H}), 3.63\left(\mathrm{dd}, 1 \mathrm{H}, J_{1}=4.0 \mathrm{~Hz}, J_{2}=9.2 \mathrm{~Hz}\right), 3.73(\mathrm{~s}, 3 \mathrm{H}), 4.07$ $(\mathrm{m}$, $1 \mathrm{H}$ ), 4.49-4.52 (m, 2H), $6.55(\mathrm{~d}, J=8.8 \mathrm{~Hz}, 2 \mathrm{H}), 6.74(\mathrm{~d}, J=8.8 \mathrm{~Hz}, 2 \mathrm{H}), 7.33(\mathrm{~m}, 5 \mathrm{H}) ;{ }^{13} \mathrm{C}$ NMR $\left(\mathrm{CDCl}_{3}, 100 \mathrm{MHz}\right): \delta 27.58,55.23,55.66,68.31,69.47,73.45,114.91,115.17,127.87,127.98$, 128.48, 137.50, 139.72, 152.80, 204.45; HRMS for $\mathrm{C}_{19} \mathrm{H}_{22} \mathrm{~N}_{4} \mathrm{O}_{3}\left(\mathrm{MH}^{+}\right)$: calcd 355.1765, obsd 355.1766; HPLC (Daicel Chirapak AD, hexane/isopropanol $=98: 2$, flow rate $1.0 \mathrm{~mL} / \mathrm{min}, \lambda=$ $254 \mathrm{~nm}): \mathrm{t}_{\mathrm{R}}=20.75 \min \left(\right.$ syn, minor), $\mathrm{t}_{\mathrm{R}}=23.81 \min$ (syn, major), $\mathrm{t}_{\mathrm{R}}=25.07 \min$ (anti, minor), $\mathrm{t}_{\mathrm{R}}=26.67 \min$ (anti, major).

\section{(4S,5S)-4-azido-6-(benzyloxy)-5-(4-methoxyphenylamino)hexan-3-}

one (8): To a glass vial charged with benzyloxyacetaldehyde $(0.5 \mathrm{mmol})$ and $p$-anisidine $(0.5 \mathrm{mmol})$ was added DMSO $(1 \mathrm{~mL})$ and stirred at room temperature until imine formation is complete as monitored by TLC (30

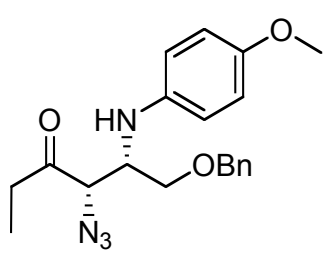
$\mathrm{min})$. Then catalyst 3 (30 mol\%) followed by azidobutanone $(0.75 \mathrm{mmol})$ was added and the reaction was stirred at room temperature for $6 \mathrm{~h}$. Then, half saturated $\mathrm{NH}_{4} \mathrm{Cl}$ solution and ethyl 
acetate were added under vigorous stirring, the layers were separated and the organic phase was washed with water. The combined organic phases were dried $\left(\mathrm{Na}_{2} \mathrm{SO}_{4}\right)$, concentrated, and purified by flash column chromatography (silica gel, mixtures of hexanes/ethyl acetate) to afford the desired Mannich product. ${ }^{1} \mathrm{H}$ NMR $\left(\mathrm{CDCl}_{3}, 400 \mathrm{MHz}\right): \delta 0.97(\mathrm{t}, J=7.2 \mathrm{~Hz}, 3 \mathrm{H}), 2.50(\mathrm{q}, J$ $=7.2 \mathrm{~Hz}, 2 \mathrm{H}), 3.46(\mathrm{t}, J=8.8 \mathrm{~Hz}, 1 \mathrm{H}), 3.62\left(\mathrm{dd}, 1 \mathrm{H}, J_{1}=4.0 \mathrm{~Hz}, J_{2}=9.2 \mathrm{~Hz}\right), 3.73(\mathrm{~s}, 3 \mathrm{H}), 4.07$ $(\mathrm{m}$, ), 4.44-4.52 (m, 2H), $6.55(\mathrm{~d}, J=8.8 \mathrm{~Hz}, 2 \mathrm{H}), 6.74(\mathrm{~d}, J=8.8 \mathrm{~Hz}, 2 \mathrm{H}), 7.32(\mathrm{~m}, 5 \mathrm{H}) ;{ }^{13} \mathrm{C} \mathrm{NMR}$ $\left(\mathrm{CDCl}_{3}, 100 \mathrm{MHz}\right): \delta 7.27,33.37,55.35,55.68,68.40,69.09,73.45,114.91,127.88,128.48$, 137.52, 139.81, 152.77, 207.19; HRMS for $\mathrm{C}_{20} \mathrm{H}_{24} \mathrm{~N}_{4} \mathrm{O}_{3}\left(\mathrm{MH}^{+}\right)$: calcd 369.1921, obsd 369.1924; HPLC (Daicel Chiralcel OJ-H, hexane/isopropanol $=85: 15$, flow rate $1.0 \mathrm{~mL} / \mathrm{min}, \lambda=254$ $\mathrm{nm}): \mathrm{t}_{\mathrm{R}}=37.55 \min ($ anti, minor $), \mathrm{t}_{\mathrm{R}}=42.08 \min ($ syn, minor $), \mathrm{t}_{\mathrm{R}}=44.24 \min ($ syn, major $), \mathrm{t}_{\mathrm{R}}=$ 66.08 min (anti, major).

1,2-Azido amine (9). To a glass vial charged with aldehyde $(0.5 \mathrm{mmol})$ and $p$-anisidine $(0.5 \mathrm{mmol})$ was added DMSO $(1 \mathrm{~mL})$ and stirred at room temperature until imine formation is complete as monitored by TLC ( $1 \mathrm{~h})$. Then catalyst 3 (30 mol\%) followed by azidoacetone $(0.75$ mmol) was added and the reaction was stirred at room temperature for 36 h. Then, half saturated $\mathrm{NH}_{4} \mathrm{Cl}$ solution and ethyl acetate were added

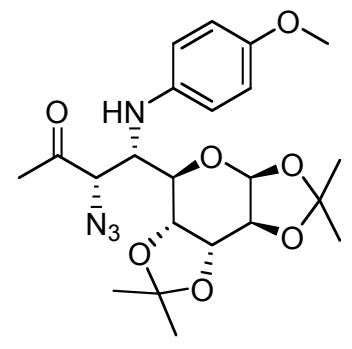
under vigorous stirring, the layers were separated and the organic phase was washed with water. The combined organic phases were dried $\left(\mathrm{Na}_{2} \mathrm{SO}_{4}\right)$, concentrated, and purified by flash column chromatography (silica gel, mixtures of hexanes/ethyl acetate) to afford the desired Mannich product. ${ }^{1} \mathrm{H}$ NMR $\left(\mathrm{CDCl}_{3}, 400 \mathrm{MHz}\right): \delta 1.31(\mathrm{~s}, 3 \mathrm{H}), 1.34(\mathrm{~s}, 3 \mathrm{H}), 1.50(\mathrm{~s}, 3 \mathrm{H}), 1.53(\mathrm{~s}, 3 \mathrm{H})$, $2.04(\mathrm{~s}, 1 \mathrm{H}), 2.19(\mathrm{~s}, 3 \mathrm{H}), 3.73(\mathrm{~s}, 3 \mathrm{H}), 3.87(\mathrm{~m}, 1 \mathrm{H}), 3.89(\mathrm{~m}, 1 \mathrm{H}), 4.09(\mathrm{~m}, 1 \mathrm{H}), 4.28\left(\mathrm{dd}, J_{1}=\right.$ $\left.8.0, J_{2}=2.0 \mathrm{~Hz}, 1 \mathrm{H}\right), 4.30\left(\mathrm{dd}, J_{1}=5.2, J_{2}=2.4 \mathrm{~Hz}, 1 \mathrm{H}\right), 4.43(\mathrm{~d}, J=3.2 \mathrm{~Hz}, 1 \mathrm{H}), 4.62\left(\mathrm{dd}, J_{1}=\right.$ $\left.7.6 \mathrm{~Hz}, J_{2}=2.4 \mathrm{~Hz}, 1 \mathrm{H}\right), 5.51(\mathrm{~d}, J=5.2 \mathrm{~Hz}, 1 \mathrm{H}), 6.61(\mathrm{~d}, J=8.8 \mathrm{~Hz}, 2 \mathrm{H}), 6.73(\mathrm{~d}, J=8.8 \mathrm{~Hz}$, 2H); HRMS for $\mathrm{C}_{22} \mathrm{H}_{30} \mathrm{~N}_{4} \mathrm{O}_{7}\left(\mathrm{MH}^{+}\right)$: calcd 463.2187, obsd 463.2183. 


\section{(2S,3S)-ethyl-3-(tert-butoxycarbonylamino)-2-(4-}

methoxyphenylamino)-4-oxo-4-phenylbutanoate (10): $10 \% \mathrm{Pd} / \mathrm{C}$

$(1 \mathrm{mg})$ in ethyl acetate $(250 \mu \mathrm{L})$ was treated with hydrogen $(1$ atmasphere) for $10 \mathrm{~min}$. Then Mannich product 3 (6 mg, $16 \mu \mathrm{mol}$ ) and $\mathrm{Boc}_{2} \mathrm{O}(4.3 \mathrm{mg}, 19 \mu \mathrm{mol})$ in ethyl acetate $(250 \mu \mathrm{L})$ were added

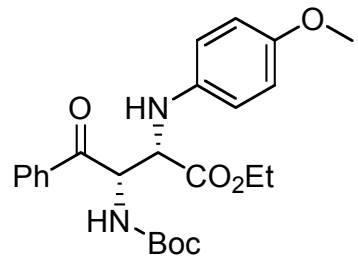
and stirred under hydrogen atmosphere for $48 \mathrm{~h}$. Reaction mixture was filtered over celite and washed with ethyl acetate $(3 \mathrm{~mL}) .{ }^{1} \mathrm{H}$ NMR of the concentrated crude compound shows complete conversion of azide to Boc protected amine. Purification by flash column chromatography (silica gel, mixtures of hexanes/ethyl acetate) provided analytically pure compound 10. ${ }^{1} \mathrm{H}$ NMR $\left(\mathrm{CDCl}_{3}, 400 \mathrm{MHz}\right): \delta 1.14$ (t, J=5.2 Hz, $\left.3 \mathrm{H}\right), 1.46$ (s, 9H), 3.74 (s, 3H), 4.02 (m, 2 H), 4.39 (m, 1H), 5.73 (m, 2H), 6.66 (m, 2H), $6.76(\mathrm{~m}, 2 \mathrm{H}), 7.49$ (m, $2 \mathrm{H}), 7.61$ $(\mathrm{m}, 1 \mathrm{H}), 8.00(\mathrm{~m}, 2 \mathrm{H}) ;{ }^{13} \mathrm{C} \mathrm{NMR}\left(\mathrm{CDCl}_{3}, 100 \mathrm{MHz}\right): \delta 14.01,28.27,29.69,55.67,61.52$, $80.61,114.66,114.79,116.05,116.29,128.75,128.84,128.95,133.93,134.94,153.35,170.59$, 197.07; HRMS for $\mathrm{C}_{24} \mathrm{H}_{30} \mathrm{~N}_{2} \mathrm{O}_{6}\left(\mathrm{MH}^{+}\right)$: calcd 443.2177, obsd 443.2169; HPLC (Daicel Chirapak $\mathrm{AD}$, hexane/isopropanol $=85: 15$, flow rate $1.0 \mathrm{~mL} / \mathrm{min}, \lambda=254 \mathrm{~nm}): \mathrm{t}_{\mathrm{R}}=12.13 \mathrm{~min}$ (anti, minor), $\mathrm{t}_{\mathrm{R}}=18.40 \min ($ syn, major $), \mathrm{t}_{\mathrm{R}}=27.57 \min ($ syn, minor $), \mathrm{t}_{\mathrm{R}}=32.43 \min$ (anti, major).

\section{(S)-ethyl-5-(1,3-dioxoisoindolin-2-yl)-2-(4-}

methoxyphenylamino)-4-oxopentanoate (11): To a glass vial charged with $\alpha$-imino ethyl glyoxylate (104 mg, $0.5 \mathrm{mmol}$ ) in NMP $(1 \mathrm{~mL})$ was added phthalimido acetone $(0.75 \mathrm{mmol})$ followed by catalyst 3 (30 mol\%) and the reaction was stirred at $4{ }^{\circ} \mathrm{C}$ for $60 \mathrm{~h}$. Then, a half saturated $\mathrm{NH}_{4} \mathrm{Cl}$ solution and ethyl acetate were added with vigorous stirring, the layers were separated and the organic

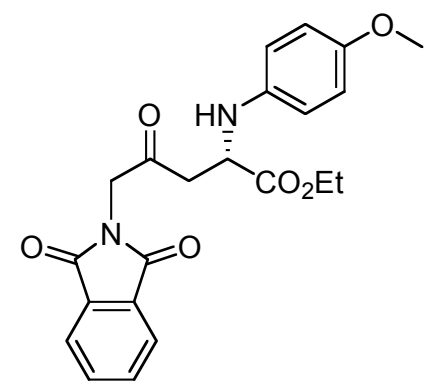
phase was washed with water. The combined organic phases were dried $\left(\mathrm{Na}_{2} \mathrm{SO}_{4}\right)$, concentrated, and purified by flash column chromatography (silica gel, mixtures of hexanes/ethyl acetate) to afford the desired Mannich product. ${ }^{1} \mathrm{H} \mathrm{NMR}\left(\mathrm{CDCl}_{3}, 400 \mathrm{MHz}\right): \delta 1.26(\mathrm{t}, 3 \mathrm{H}, J=7.2 \mathrm{~Hz})$, $3.05\left(\mathrm{dd}, J_{1}=5.6, J_{2}=1.2 \mathrm{~Hz}, 1 \mathrm{H}\right), 3.74(\mathrm{~s}, 3 \mathrm{H}), 4.20(\mathrm{~m}, 2 \mathrm{H}), 4.41(\mathrm{~m}, 1 \mathrm{H}), 4.52(\mathrm{~m}, 2 \mathrm{H}), 6.67$ $(\mathrm{d}, J=8.8 \mathrm{~Hz}, 2 \mathrm{H}), 6.78(\mathrm{~d}, J=8.8 \mathrm{~Hz}, 2 \mathrm{H}), 7.74(\mathrm{~m}, 2 \mathrm{H}), 7.87(\mathrm{~m}, 2 \mathrm{H}) ;{ }^{13} \mathrm{C} \mathrm{NMR}\left(\mathrm{CDCl}_{3}, 100\right.$ 
$\mathrm{MHz}): \delta 14.09,42.13,47.01,54.22,55.66,61.78,114.86,115.89,123.58,131.97,134.20$, 140.08, 167.46, 172.36; HRMS for $\mathrm{C}_{22} \mathrm{H}_{22} \mathrm{~N}_{2} \mathrm{O}_{6}\left(\mathrm{MH}^{+}\right)$: calcd 411.1551, obsd 411.1549; HPLC (Daicel Chiralcel OD-H, hexane/isopropanol $=90: 10$, flow rate $1.0 \mathrm{~mL} / \mathrm{min}, \lambda=254 \mathrm{~nm}$ ): $\mathrm{t}_{\mathrm{R}}=$ 63.17 min (major), $\mathrm{t}_{\mathrm{R}}=81.49$ (minor).

\section{(S)-2-(4-(4-methoxyphenylamino)-4-(4-nitrophenyl)-2-}

oxobutyl)isoindoline-1,3-dione (12): To a glass vial charged with $p$-nitrobenzaldehyde imine $(0.5 \mathrm{mmol})$ in NMP $(1 \mathrm{~mL})$ was added phthalimido acetone $(0.75 \mathrm{mmol})$ followed by catalyst 3 (30 $\mathrm{mol} \%$ ) and the reaction was stirred at $4{ }^{\circ} \mathrm{C}$ for $84 \mathrm{~h}$. Then, a half saturated $\mathrm{NH}_{4} \mathrm{Cl}$ solution and ethyl acetate were added with

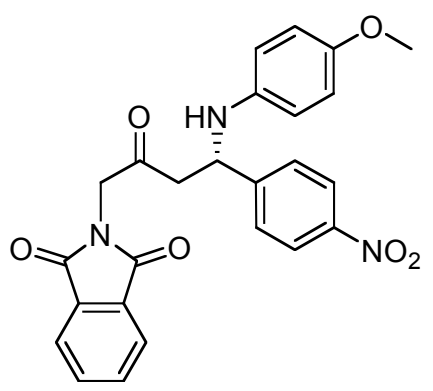
vigorous stirring, the layers were separated and the organic phase was washed with water. The combined organic phases were dried $\left(\mathrm{Na}_{2} \mathrm{SO}_{4}\right)$, concentrated, and purified by flash column chromatography (silica gel, mixtures of hexanes/ethyl acetate) to afford the desired Mannich product. ${ }^{1} \mathrm{H} \mathrm{NMR}\left(\mathrm{CDCl}_{3}, 300 \mathrm{MHz}\right): \delta 3.05(\mathrm{~m}, 2 \mathrm{H}), 3.69(\mathrm{~s}, 3 \mathrm{H}), 4.43(\mathrm{~s}, 2 \mathrm{H}), 4.92$ (t, $J=6.6$ $\mathrm{Hz}, 1 \mathrm{H}), 6.47$ (d, $J=9.0 \mathrm{~Hz}, 2 \mathrm{H}), 6.69(\mathrm{~d}, J=9.0 \mathrm{~Hz}, 2 \mathrm{H}), 7.56(\mathrm{~d}, J=8.7 \mathrm{~Hz}, 2 \mathrm{H}), 7.77$ (m, 2H), $7.86(\mathrm{~m}, 2 \mathrm{H}), 8.19(\mathrm{~d}, J=8.7 \mathrm{~Hz}, 2 \mathrm{H}) ;{ }^{13} \mathrm{C} \mathrm{NMR}\left(\mathrm{CDCl}_{3}, 75 \mathrm{MHz}\right): \delta 46.93,47.11,54.65$, 55.59, 114.77, 115.62, 123.67, 124.19, 127.40, 131.84, 134.35, 139.90, 149.94, 152.91, 167.48, 200.09; HRMS for $\mathrm{C}_{25} \mathrm{H}_{21} \mathrm{~N}_{3} \mathrm{O}_{6}\left(\mathrm{MH}^{+}\right)$: calcd 460.1503, obsd 460.1496; HPLC (Daicel Chirapak $\mathrm{AD}$, hexane/isopropanol $=75: 25$, flow rate $1.0 \mathrm{~mL} / \mathrm{min}, \lambda=254 \mathrm{~nm}$ ): 64.09 min $($ major $), \mathrm{t}_{\mathrm{R}}=$ 82.32 (minor).

\section{(S)-4-(4-(1,3-dioxoisoindolin-2-yl)-1-(4-}

methoxyphenylamino)-3-oxobutyl)benzonitrile (13): To a glass vial charged with $p$-cyanobenzaldehyde $(0.5 \mathrm{mmol})$ and $p$ anisidine $(0.5 \mathrm{mmol})$ was added NMP $(1 \mathrm{~mL})$ and stirred at room temperature until imine formation is complete as monitored by TLC ( $1 \mathrm{~h})$. Then catalyst 3 (30 mol\%) followed by phthalimido acetone $(0.75 \mathrm{mmol})$ were added and stirred at $4{ }^{\circ} \mathrm{C}$ for $60 \mathrm{~h}$.

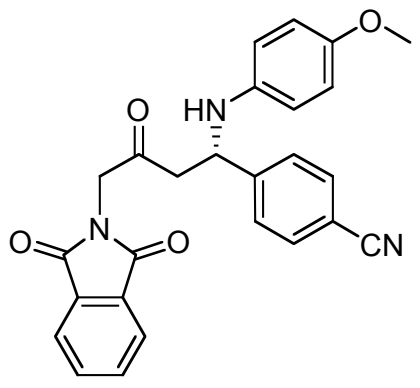
Then, half saturated $\mathrm{NH}_{4} \mathrm{Cl}$ solution and ethyl acetate were added under vigorous stirring, the 
layers were separated and the organic phase was washed with water. The combined organic phases were dried $\left(\mathrm{Na}_{2} \mathrm{SO}_{4}\right)$, concentrated, and purified by flash column chromatography (silica

gel, mixtures of hexanes/ethyl acetate) to afford the desired Mannich product. ${ }^{1} \mathrm{H} \mathrm{NMR}\left(\mathrm{CDCl}_{3}\right.$, $400 \mathrm{MHz}): \delta 3.02(\mathrm{~m}, 2 \mathrm{H}), 3.69(\mathrm{~s}, 3 \mathrm{H}), 4.24(\mathrm{~s}, 1 \mathrm{H}), 4.41(\mathrm{~s}, 2 \mathrm{H}), 4.85(\mathrm{t}, J=5.6 \mathrm{~Hz}, 1 \mathrm{H}), 6.46$ $(\mathrm{d}, J=9.2 \mathrm{~Hz}, 2 \mathrm{H}), 6.68(\mathrm{~d}, J=9.2 \mathrm{~Hz}, 2 \mathrm{H}), 7.50(\mathrm{~d}, J=8.8 \mathrm{~Hz}, 2 \mathrm{H}), 7.77(\mathrm{~d}, J=8.8 \mathrm{~Hz}, 2 \mathrm{H})$, $7.75(\mathrm{~m}, 2 \mathrm{H}), 7.86(\mathrm{~m}, 2 \mathrm{H}) ;{ }^{13} \mathrm{C} \mathrm{NMR}\left(\mathrm{CDCl}_{3}, 100 \mathrm{MHz}\right): \delta 46.96,47.12,54.84,55.58,55.61$, 111.43, 114.77, 115.58, 118.64, 123.65, 127.26, 131.86, 132.75, 134.32, 139.99, 147.89, 152.87, 167.45, 200.15; HRMS for $\mathrm{C}_{26} \mathrm{H}_{22} \mathrm{~N}_{3} \mathrm{O}_{4}\left(\mathrm{MH}^{+}\right)$: calcd 440.1605, obsd 440.1606; HPLC (Daicel Chirapak $\mathrm{AD}$, hexane/isopropanol $=75: 25$, flow rate $1.0 \mathrm{~mL} / \mathrm{min}, \lambda=254 \mathrm{~nm}): 63.90 \mathrm{~min}$ (major), $\mathrm{t}_{\mathrm{R}}=91.82$ (minor).

\section{(S)-2-(4-(4-methoxyphenylamino)-2-oxo-4-}

phenylbutyl)isoindoline-1,3-dione (14): To a glass vial charged with benzaldehyde imine $(0.5 \mathrm{mmol})$ in NMP $(1 \mathrm{~mL})$ was added phthalimido acetone $(0.75 \mathrm{mmol})$ followed by catalyst 3 (30 $\mathrm{mol} \%)$ and the reaction was stirred at $4{ }^{\circ} \mathrm{C}$ for $120 \mathrm{~h}$. Then, a half saturated $\mathrm{NH}_{4} \mathrm{Cl}$ solution and ethyl acetate were added with vigorous stirring, the layers were separated and the organic phase was washed with

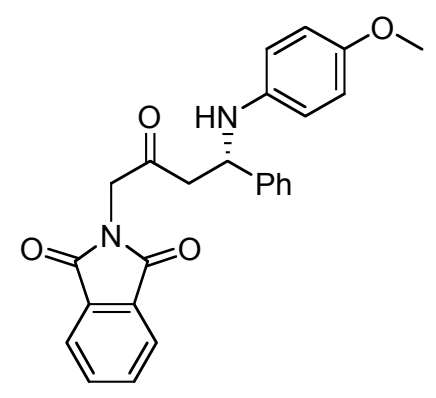
water. The combined organic phases were dried $\left(\mathrm{Na}_{2} \mathrm{SO}_{4}\right)$, concentrated, and purified by flash column chromatography (silica gel, mixtures of hexanes/ethyl acetate) to afford the desired Mannich product. ${ }^{1} \mathrm{H}$ NMR $\left(\mathrm{CDCl}_{3}, 300 \mathrm{MHz}\right): \delta 3.02(\mathrm{~m}, 2 \mathrm{H}), 3.69$ (s, 3H), $4.39(\mathrm{~s}, 2 \mathrm{H}), 4.84$ $(\mathrm{t}, J=7.2 \mathrm{~Hz}, 1 \mathrm{H}), 6.53(\mathrm{~d}, J=8.8 \mathrm{~Hz}, 2 \mathrm{H}), 6.70(\mathrm{~d}, J=8.8 \mathrm{~Hz}, 2 \mathrm{H}), 7.36(\mathrm{~m}, 5 \mathrm{H}), 7.74(\mathrm{~m}$, 2H), $7.86(\mathrm{~m}, 2 \mathrm{H}) ;{ }^{13} \mathrm{C} \mathrm{NMR}\left(\mathrm{CDCl}_{3}, 75 \mathrm{MHz}\right): \delta 47.23,47.60,55.25,55.63,114.68,115.51$, 123.57, 126.28, 127.55, 128.92, 131.94, 134.19, 140.71, 142.17, 152.48, 167.51, 200.78; HRMS for $\mathrm{C}_{25} \mathrm{H}_{22} \mathrm{~N}_{2} \mathrm{O}_{4}\left(\mathrm{MH}^{+}\right)$: calcd 415.1652, obsd 415.1642; HPLC (Daicel Chirapak AD, hexane/isopropanol $=75: 25$, flow rate $1.0 \mathrm{~mL} / \mathrm{min}, \lambda=254 \mathrm{~nm}$ ): $28.67 \min ($ major $), \mathrm{t}_{\mathrm{R}}=35.10$ (minor). 
1,4-Diamine (15). To a glass vial charged with aldehyde $(0.5 \mathrm{mmol})$ and $p$-anisidine $(0.5 \mathrm{mmol})$ was added DMSO $(1 \mathrm{~mL})$ and stirred at room temperature until imine formation is complete as monitored by TLC $(1 \mathrm{~h})$. Then catalyst 3 (30 mol\%) followed by phthalimido acetone $(0.75$ mmol) were added and stirred at room temperature for $20 \mathrm{~h}$. Then, half saturated $\mathrm{NH}_{4} \mathrm{Cl}$ solution and ethyl acetate were added under vigorous stirring, the layers were separated and the

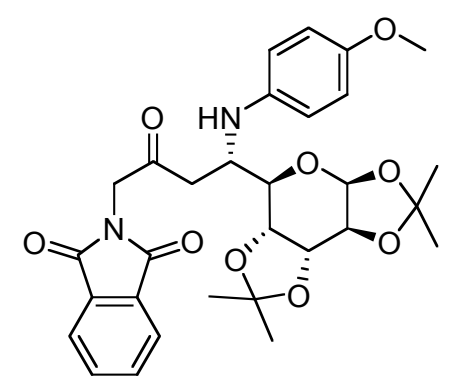
organic phase was washed with water. The combined organic phases were dried $\left(\mathrm{Na}_{2} \mathrm{SO}_{4}\right)$, concentrated, and purified by flash column chromatography (silica gel, mixtures of hexanes/ethyl acetate) to afford the desired Mannich product. ${ }^{1} \mathrm{H} \mathrm{NMR}\left(\mathrm{CDCl}_{3}, 300 \mathrm{MHz}\right): \delta$ $1.25(\mathrm{~s}, 3 \mathrm{H}), 1.31(\mathrm{~s}, 3 \mathrm{H}), 2.87(\mathrm{~m}, 1 \mathrm{H}), 3.73(\mathrm{~s}, 3 \mathrm{H}), 3.87(\mathrm{~m}, 1 \mathrm{H}), 4.29(\mathrm{~m}, 1 \mathrm{H}), 4.37(\mathrm{~m}, 1 \mathrm{H})$, $4.48-4.59(\mathrm{~m}, 2 \mathrm{H}), 5.60(\mathrm{~d}, J=3.2 \mathrm{~Hz}, 1 \mathrm{H}), 4.62\left(\mathrm{dd}, J_{1}=6.4 \mathrm{~Hz}, J_{2}=7.6 \mathrm{~Hz}, 1 \mathrm{H}\right), 5.51(\mathrm{~d}, J=$ $5.2 \mathrm{~Hz}, 1 \mathrm{H}), 6.66(\mathrm{~m}, 2 \mathrm{H}), 6.76(\mathrm{~m}, 2 \mathrm{H}), 7.73(\mathrm{~m}, 2 \mathrm{H}), 7.86(\mathrm{~m}, 2 \mathrm{H}) ;{ }^{13} \mathrm{C} \mathrm{NMR}\left(\mathrm{CDCl}_{3}, 100\right.$ MHz): $\delta 14.11,14.20,22.65,29.57,29.61,29.71,31.58,34.13,39.67,47.19,51.76,60.39$, 71.03, 108.68, 108.71, 109.23, 114.95, 114.97, 116.17, 123.43, 123.47, 132.14, 134.03, 134.04, 134.06, 140.69, 167.58, 171.14, 202.12; HRMS for $\mathrm{C}_{30} \mathrm{H}_{34} \mathrm{~N}_{2} \mathrm{O}_{9}\left(\mathrm{MH}^{+}\right)$: calcd 567.2337, obsd 567.2332 . 


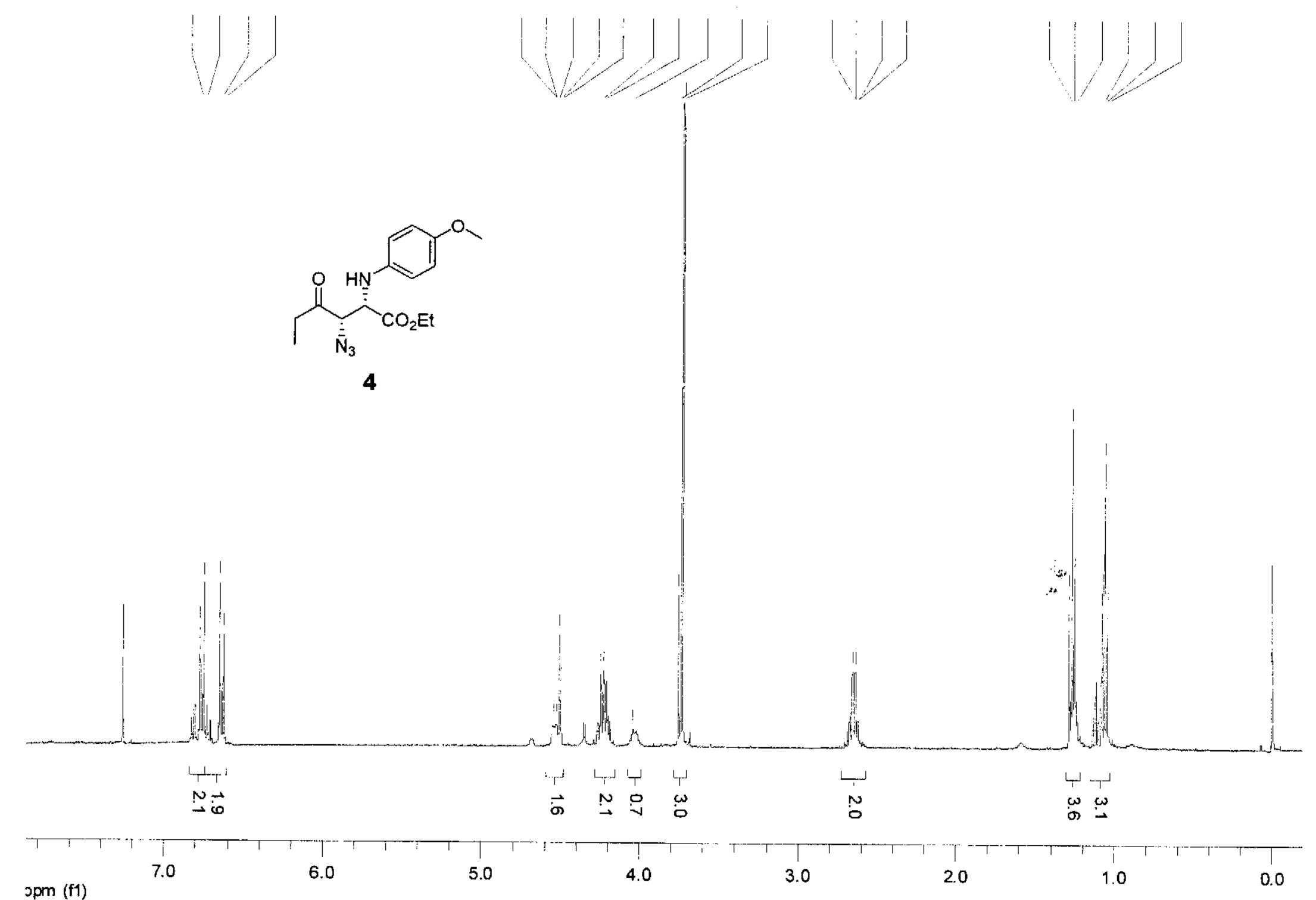




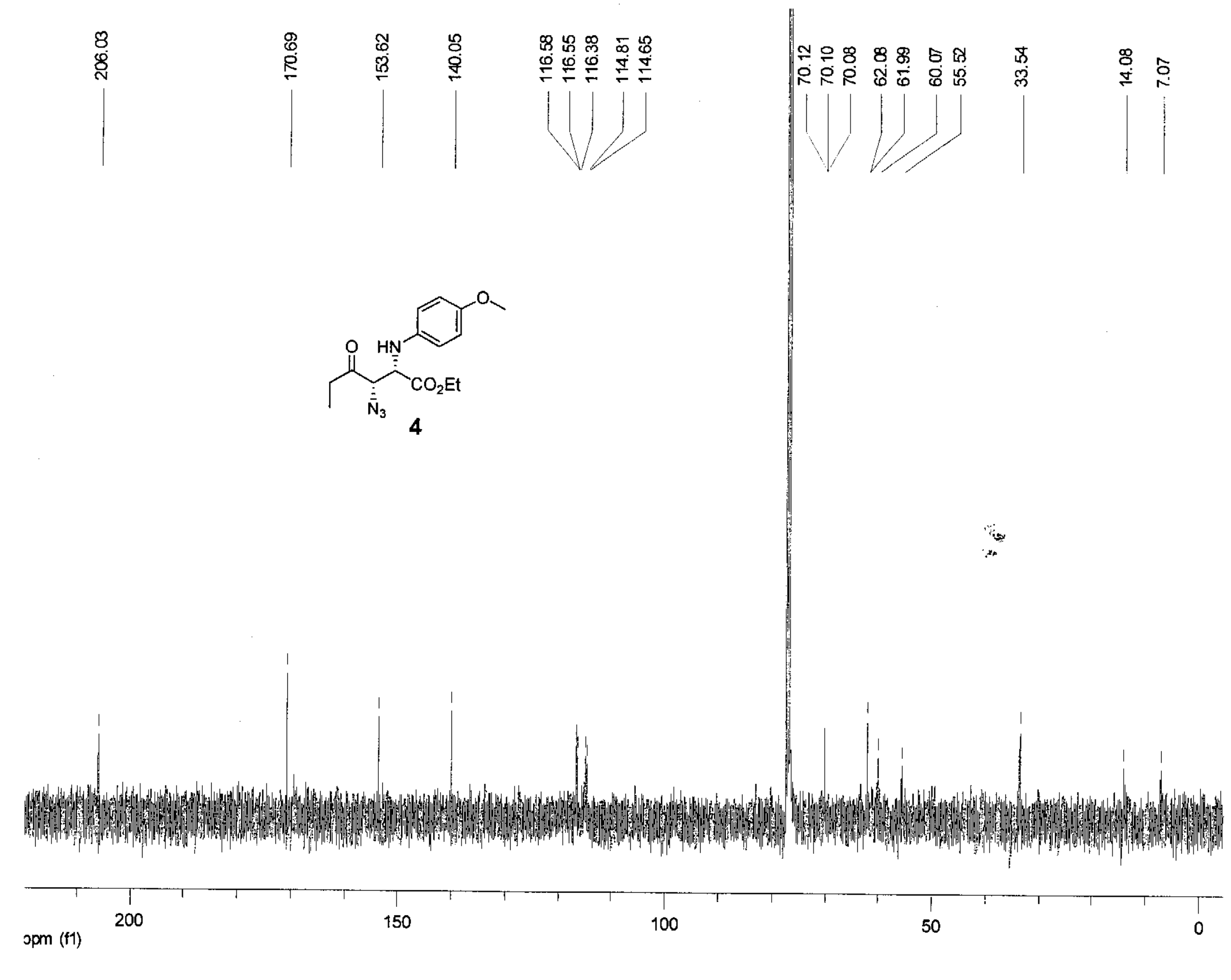




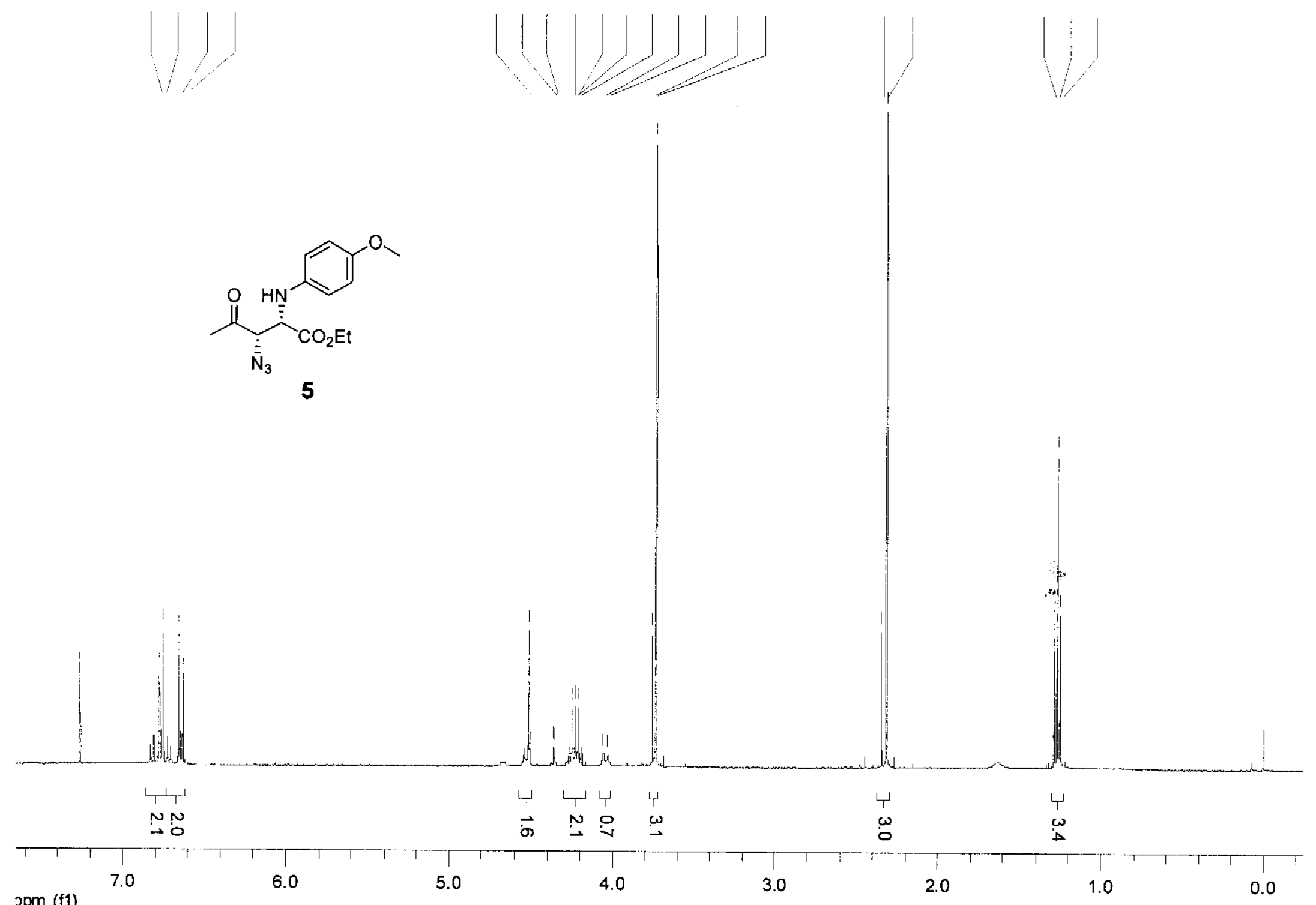



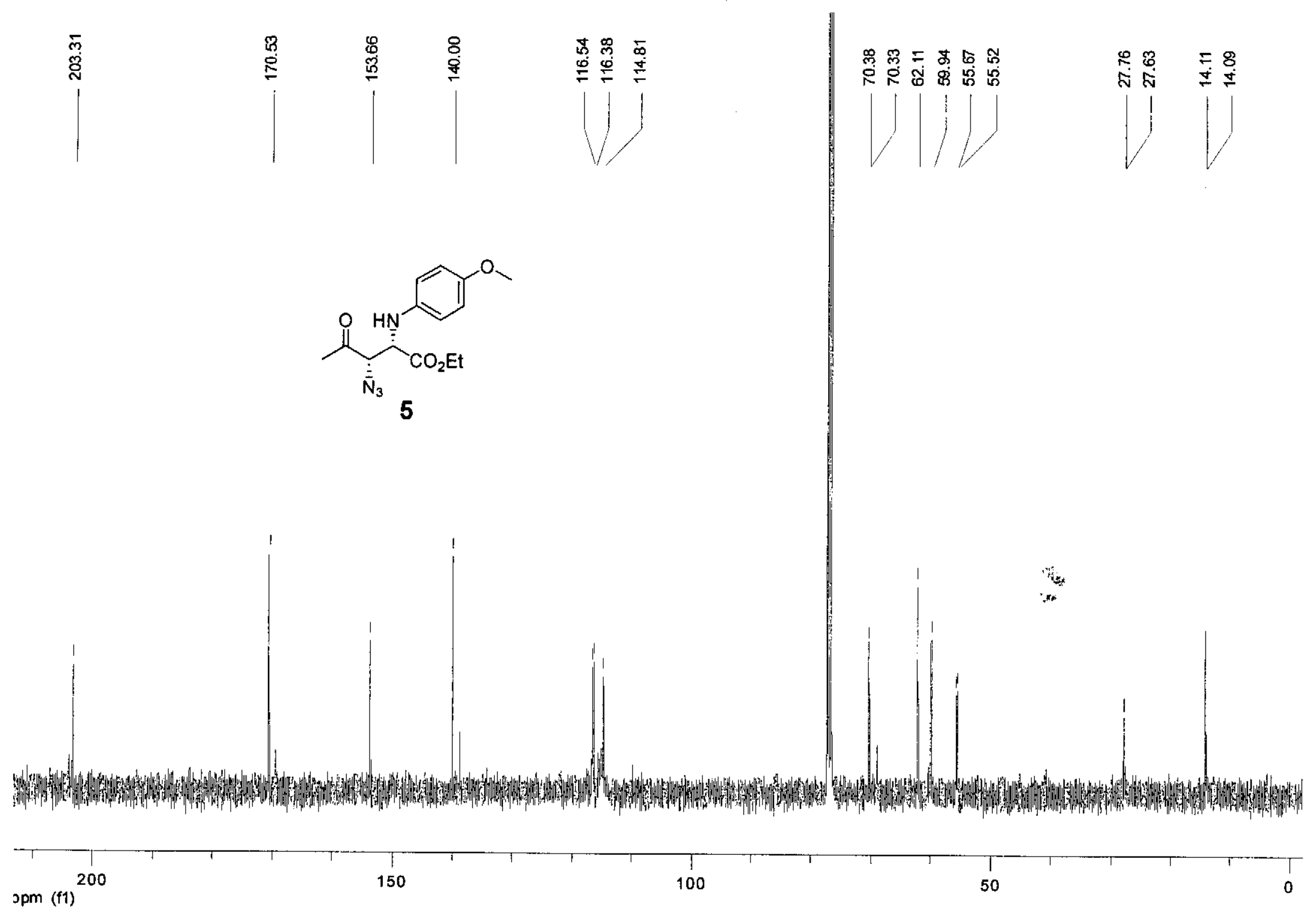

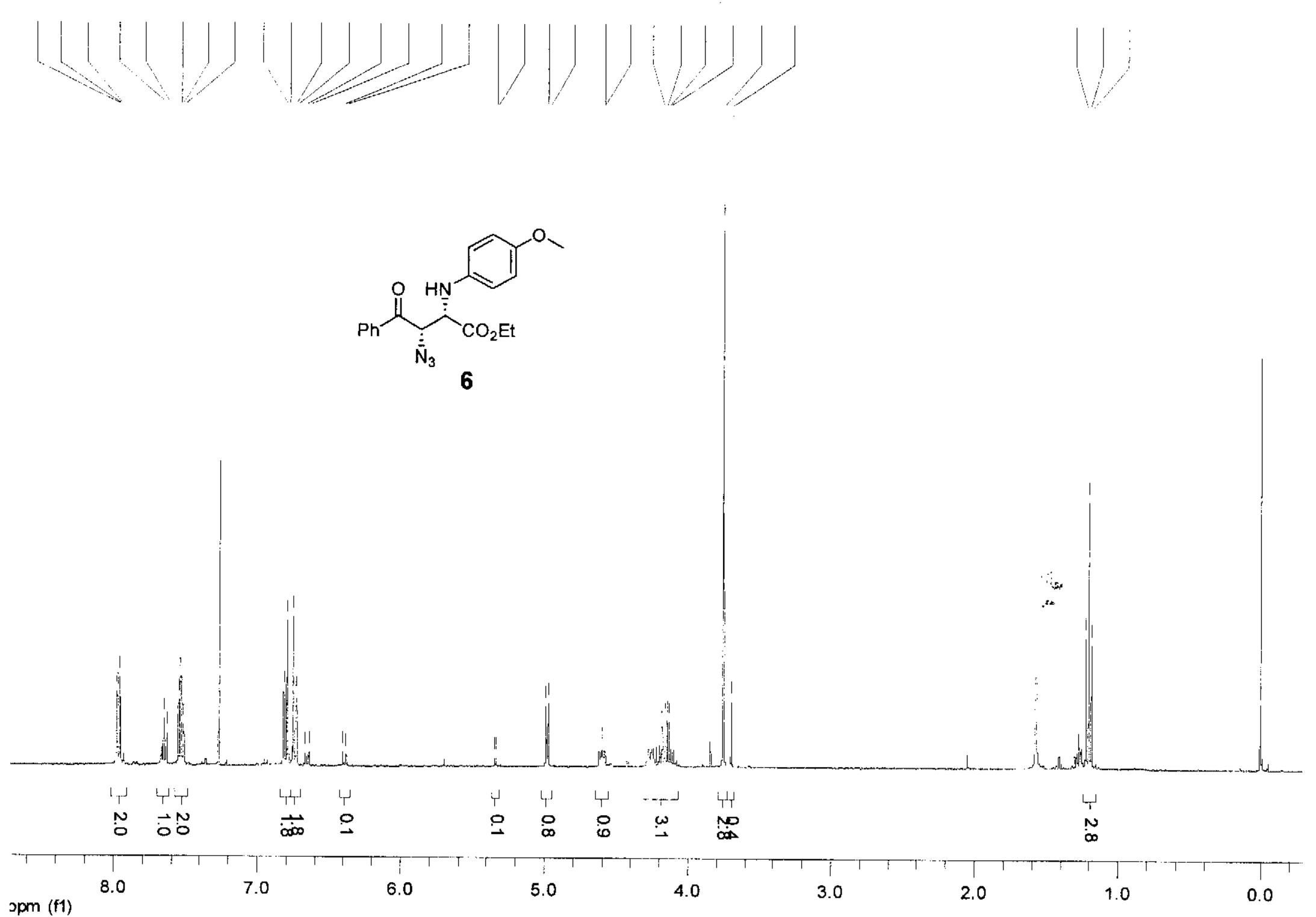


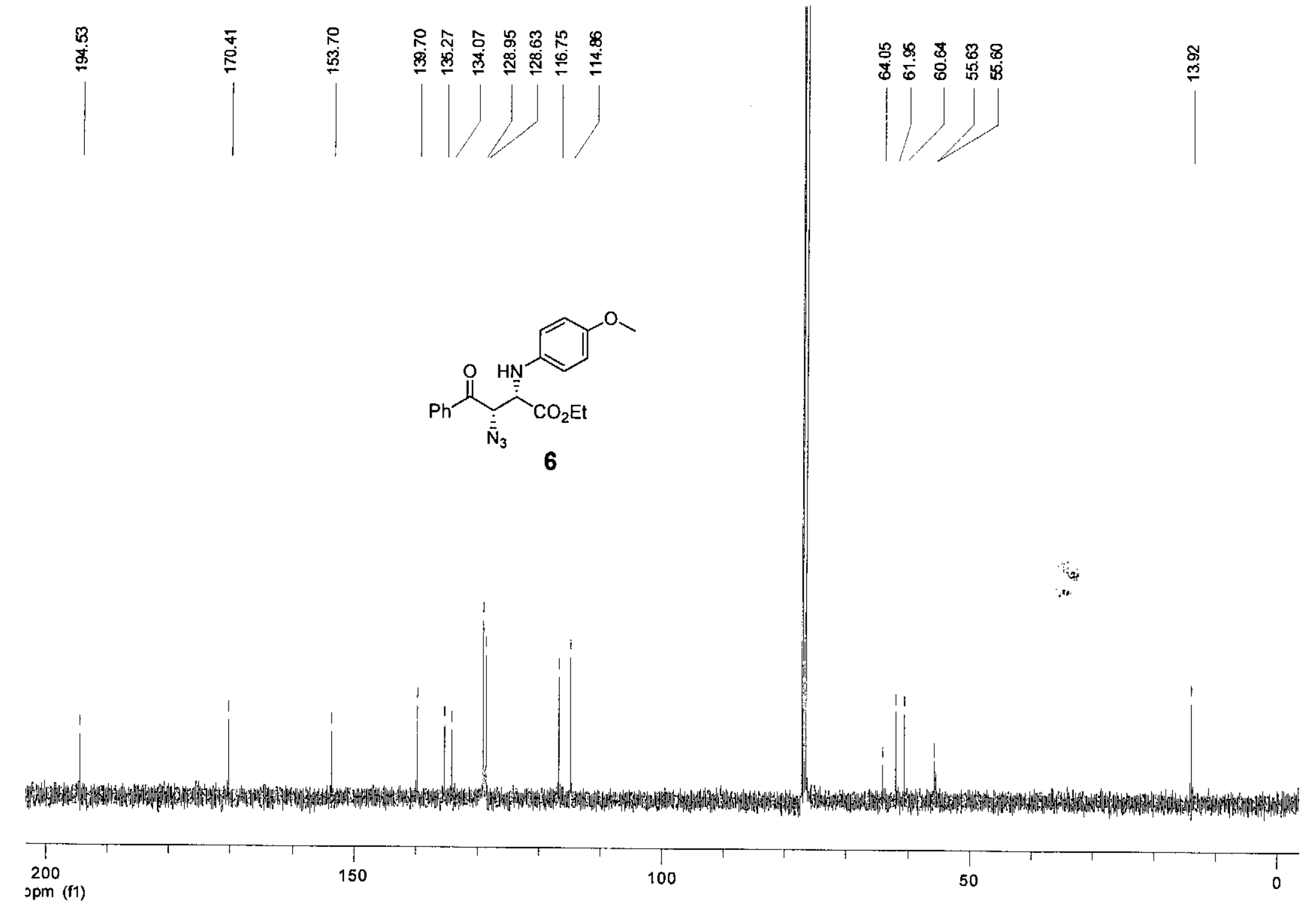




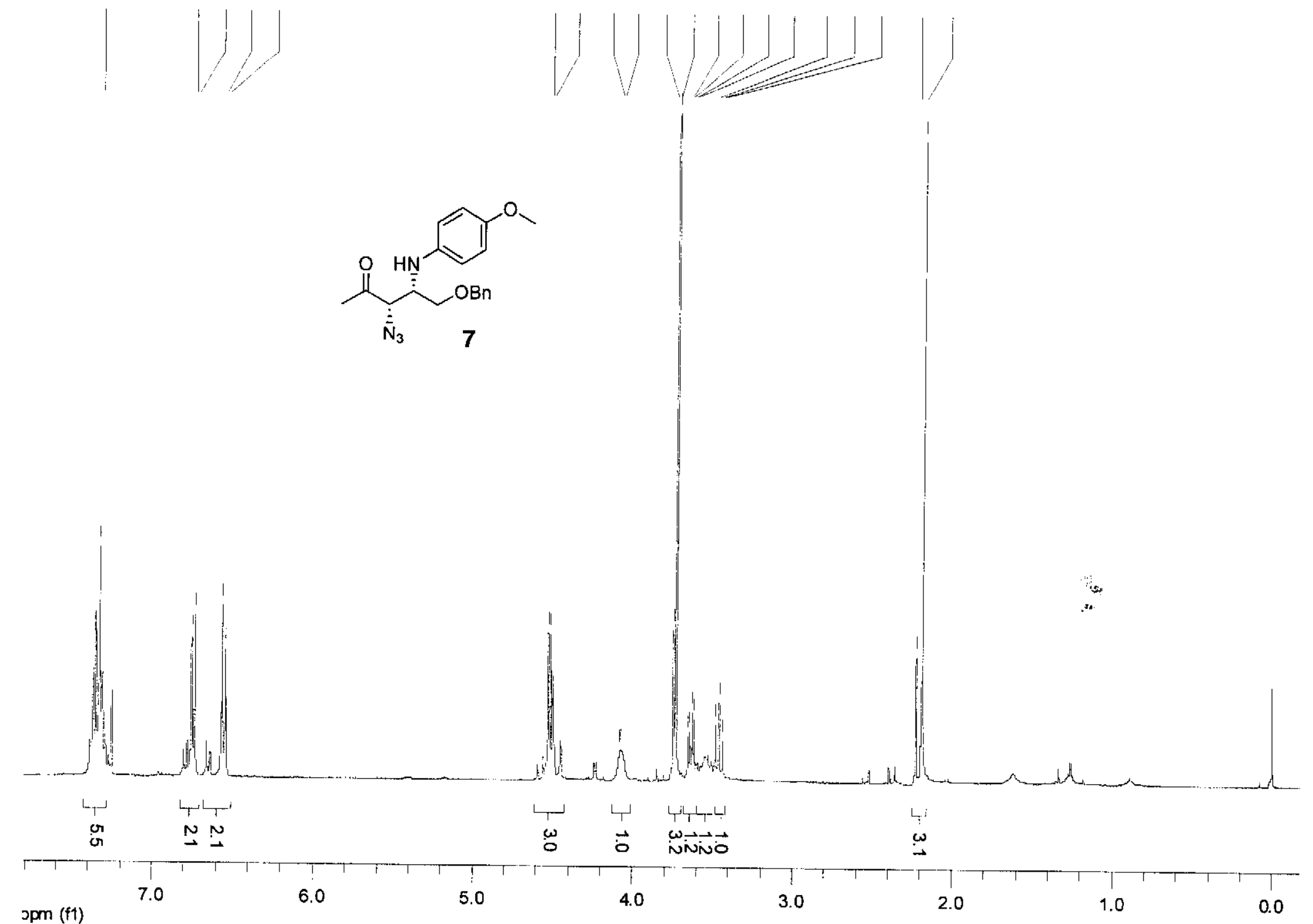



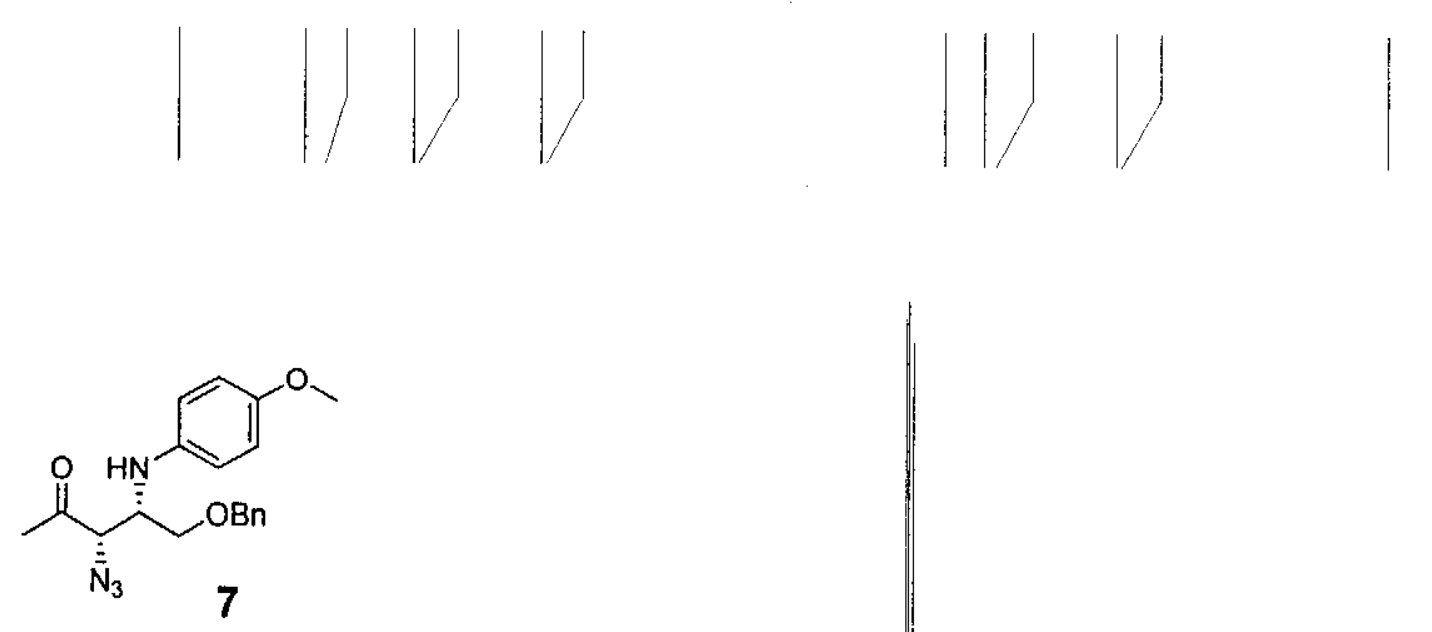

|

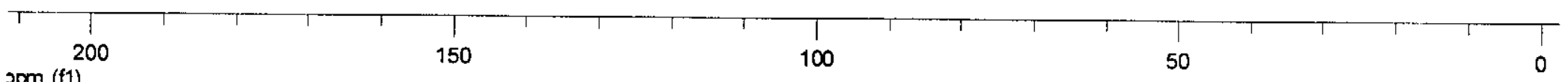




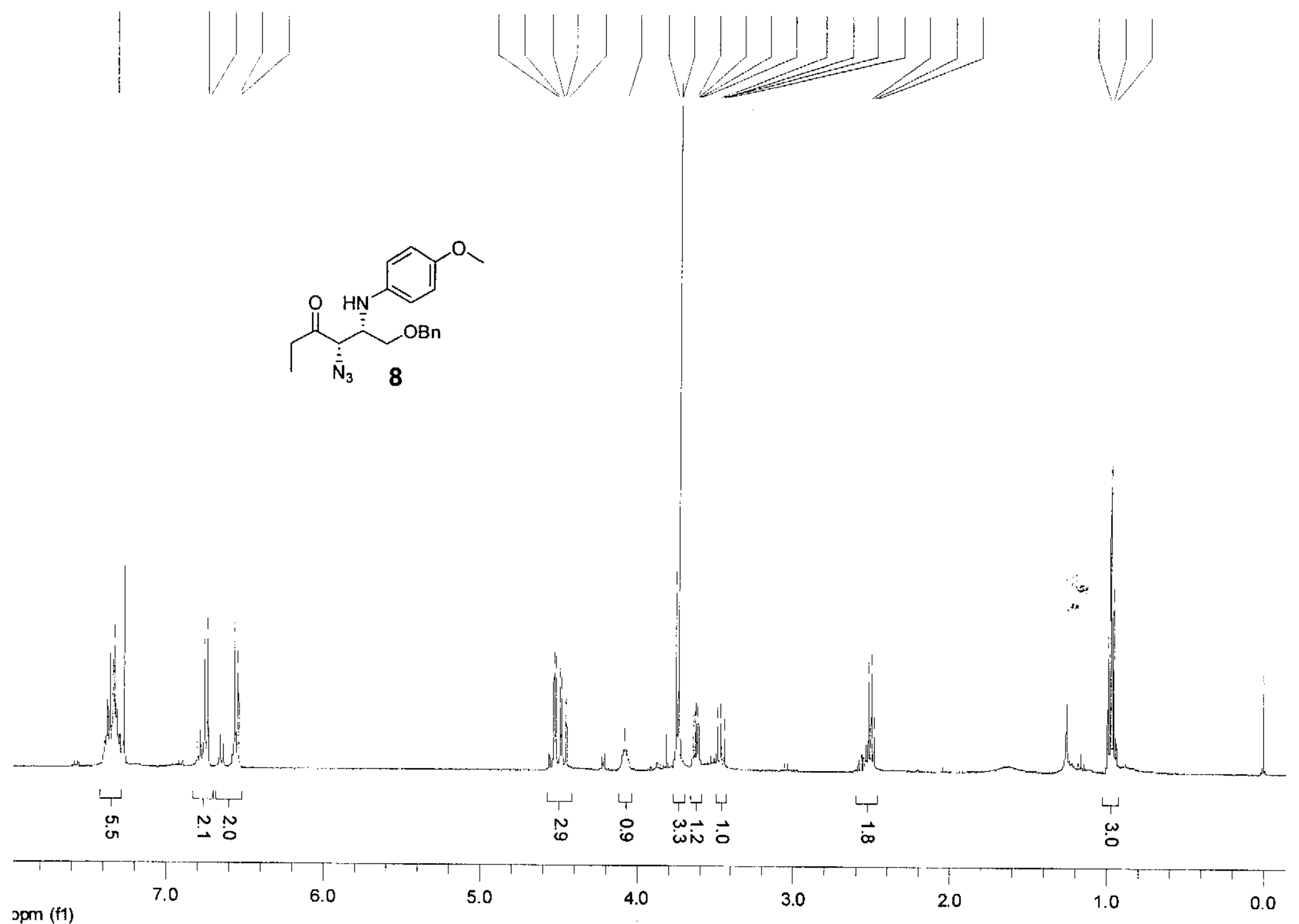




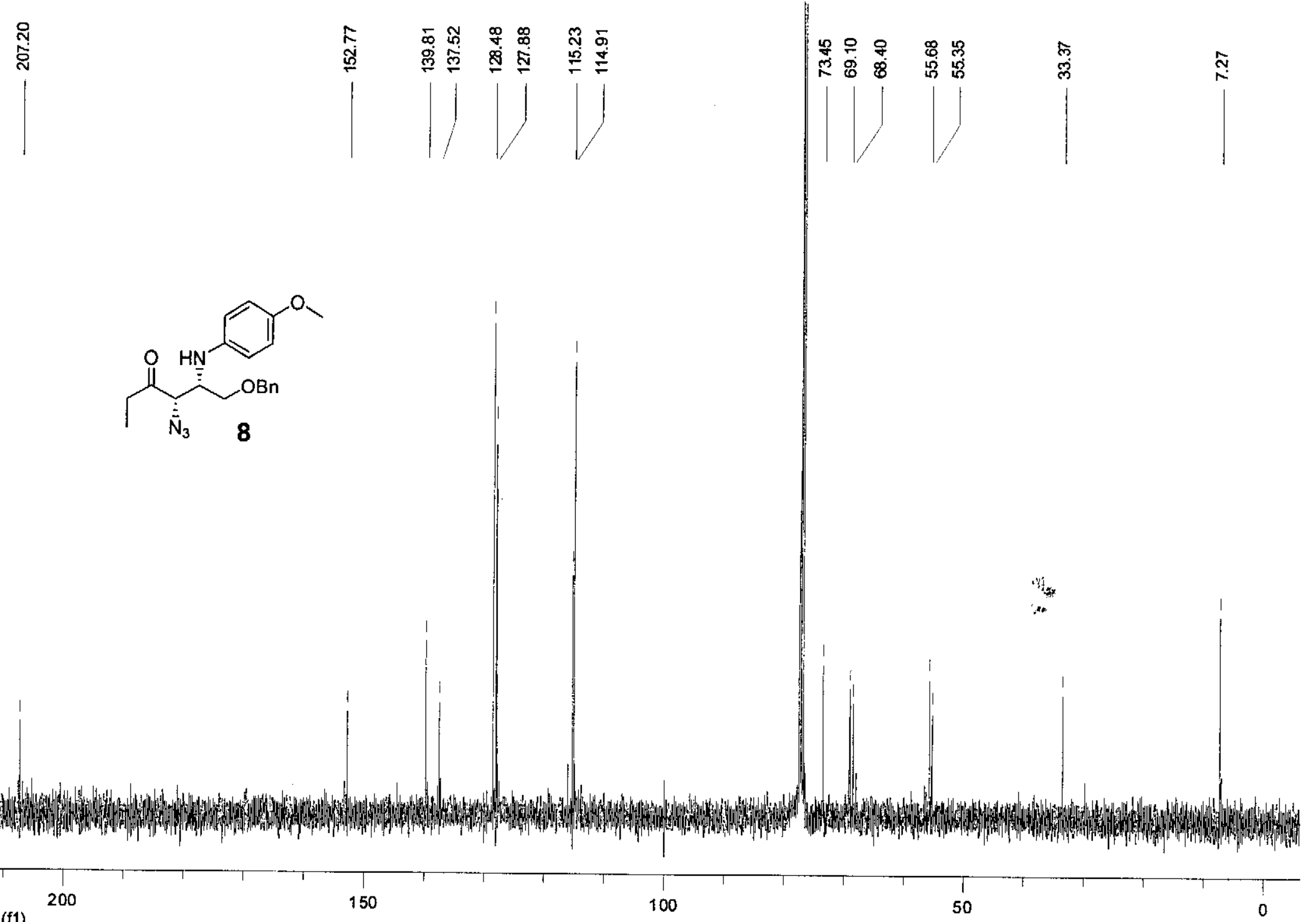




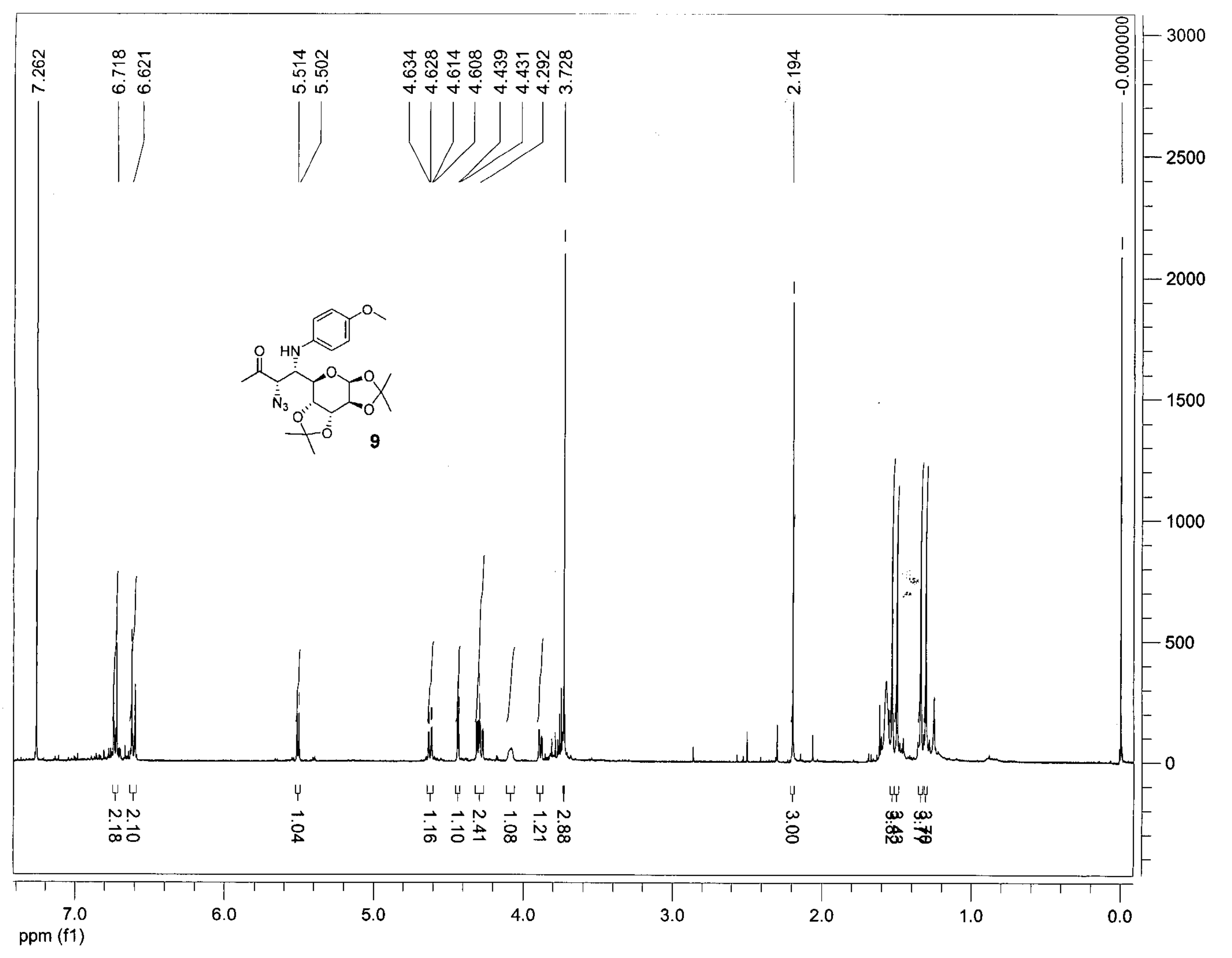




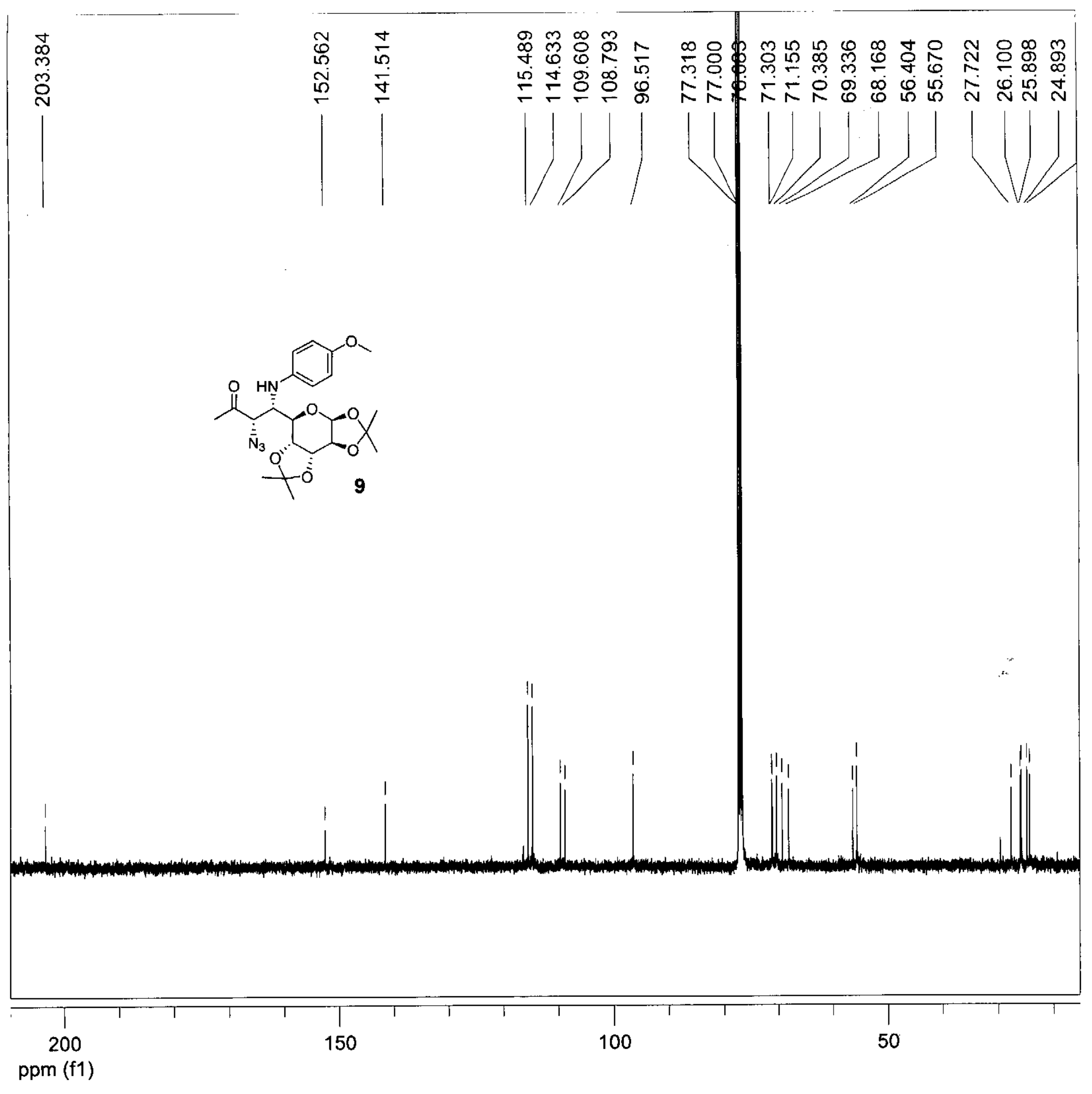



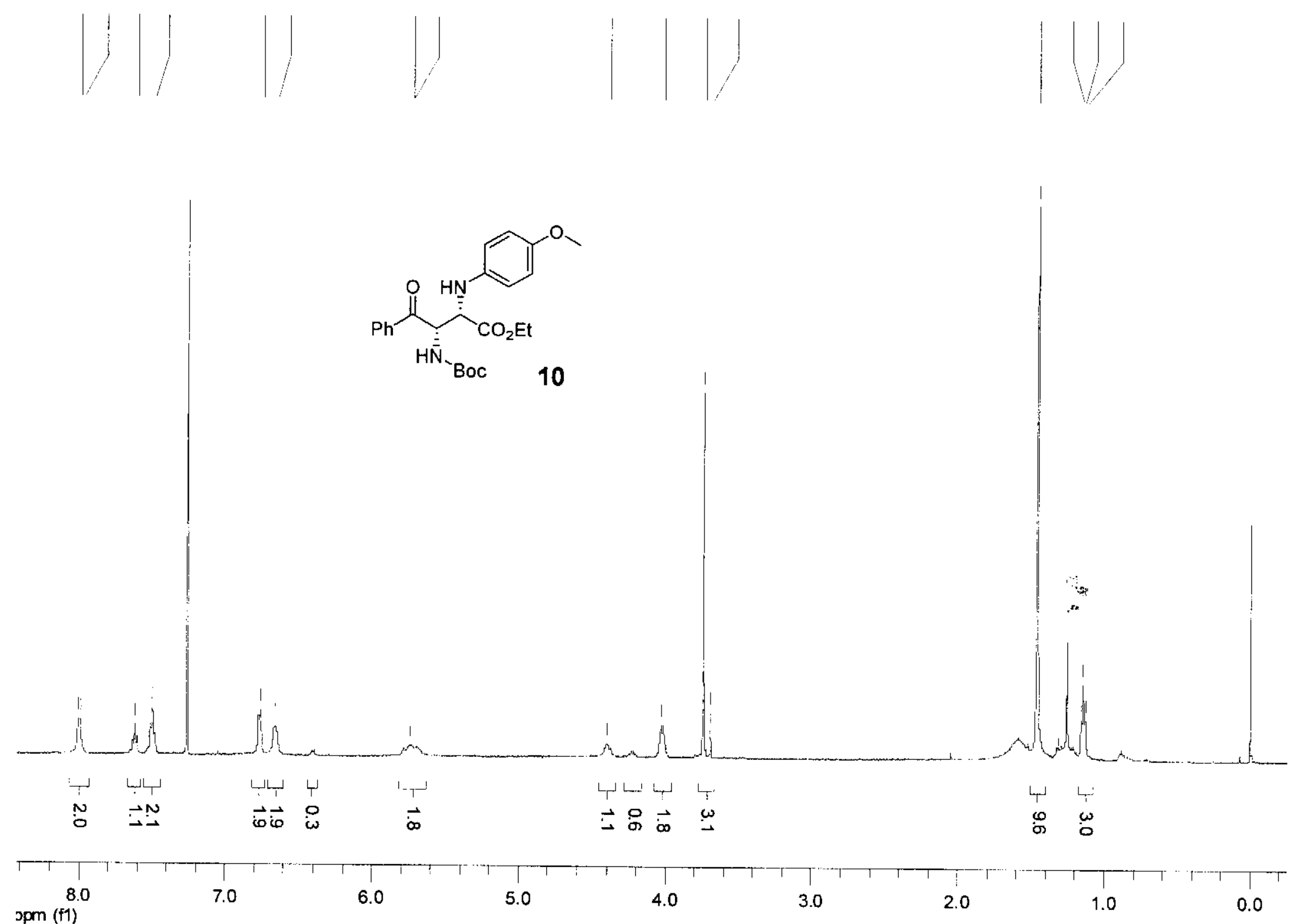


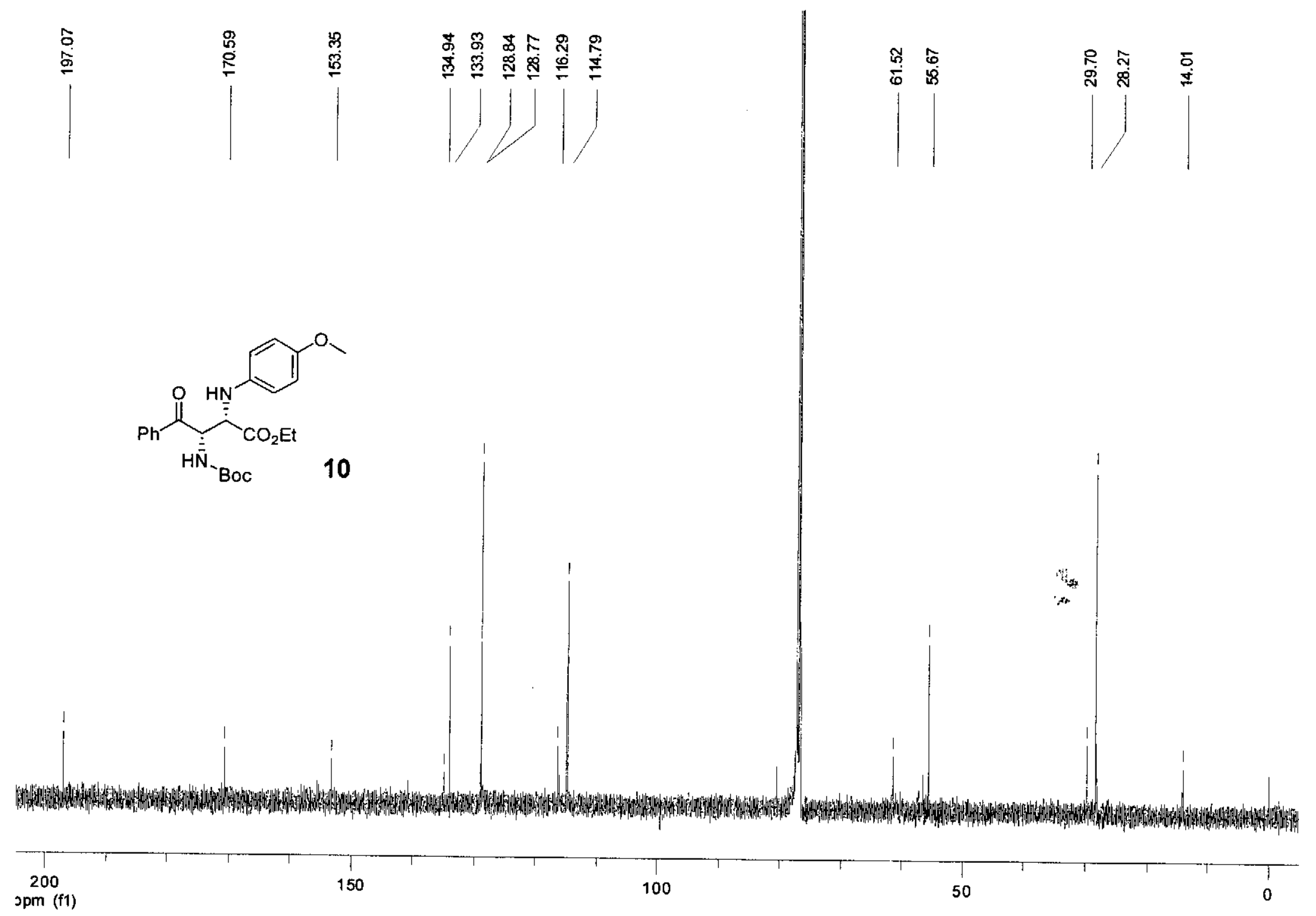




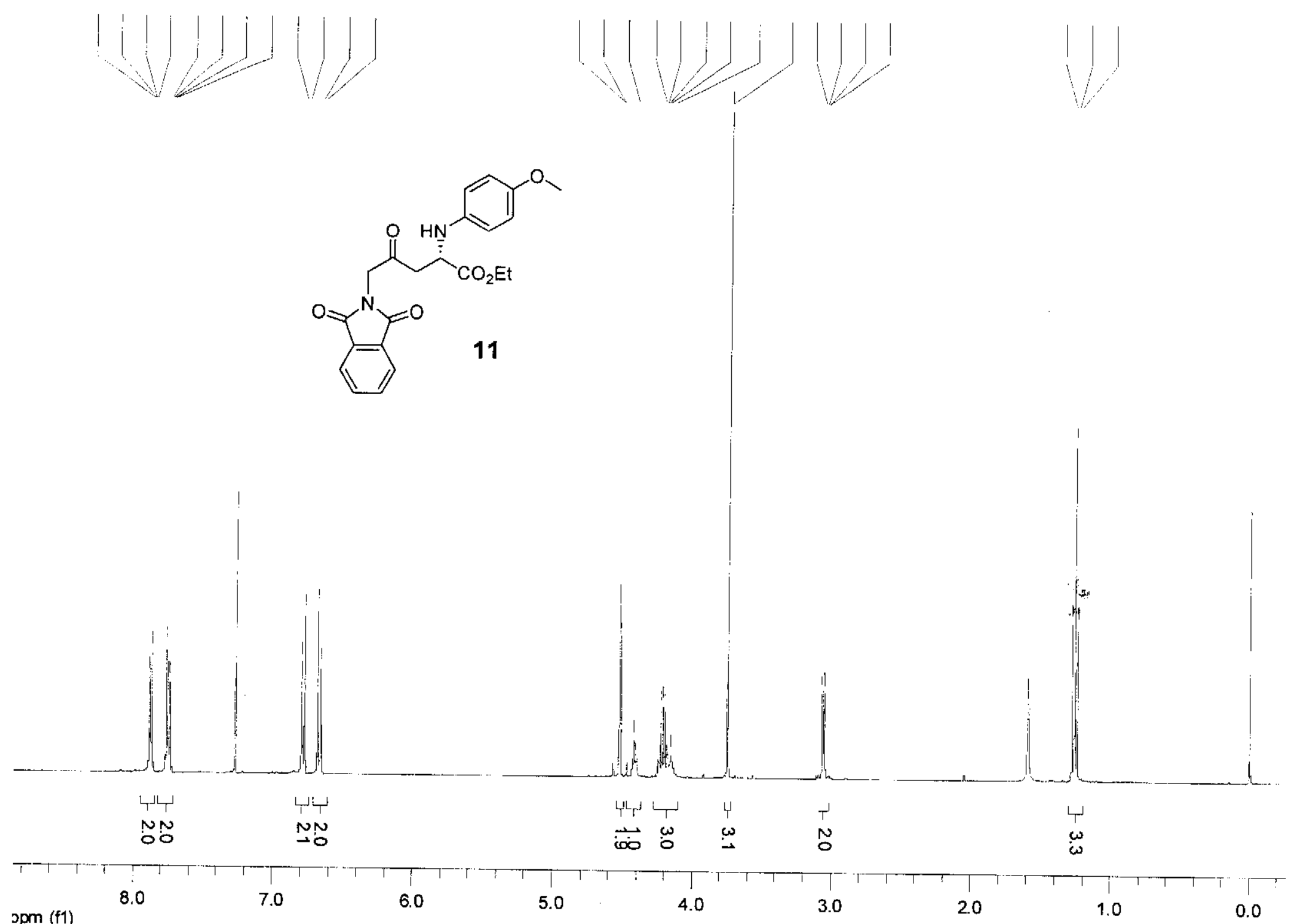



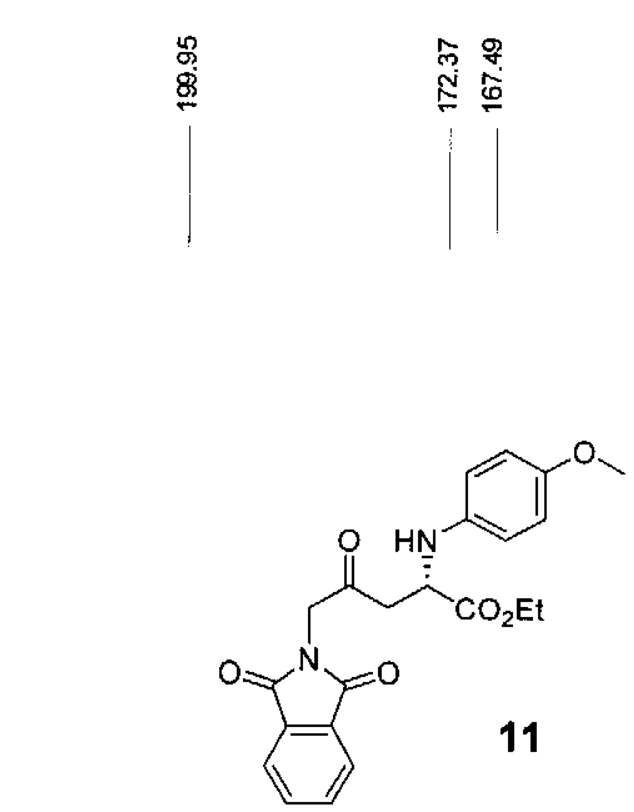
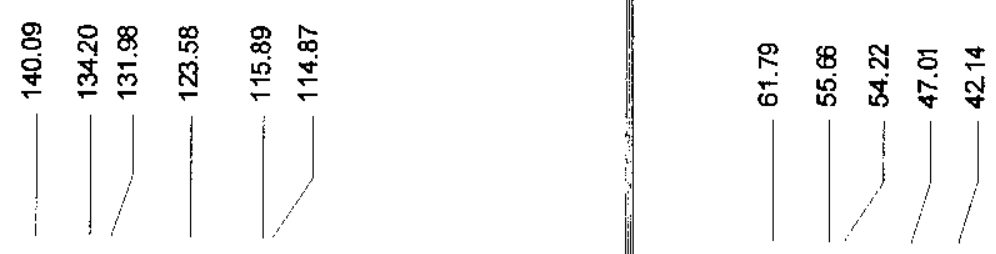

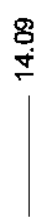

30.

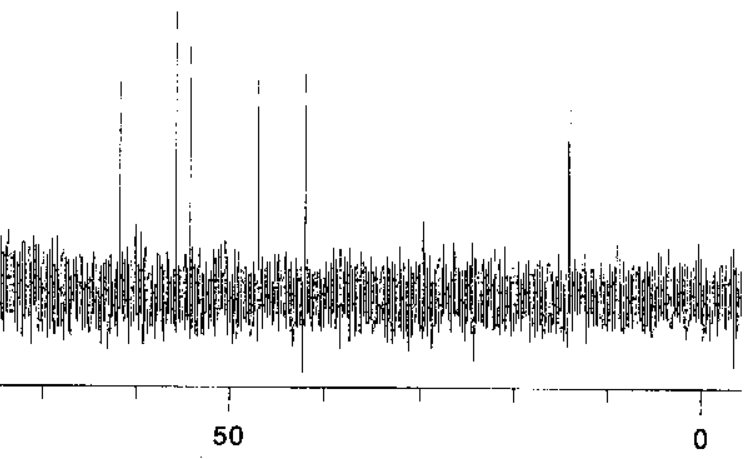

S-25 


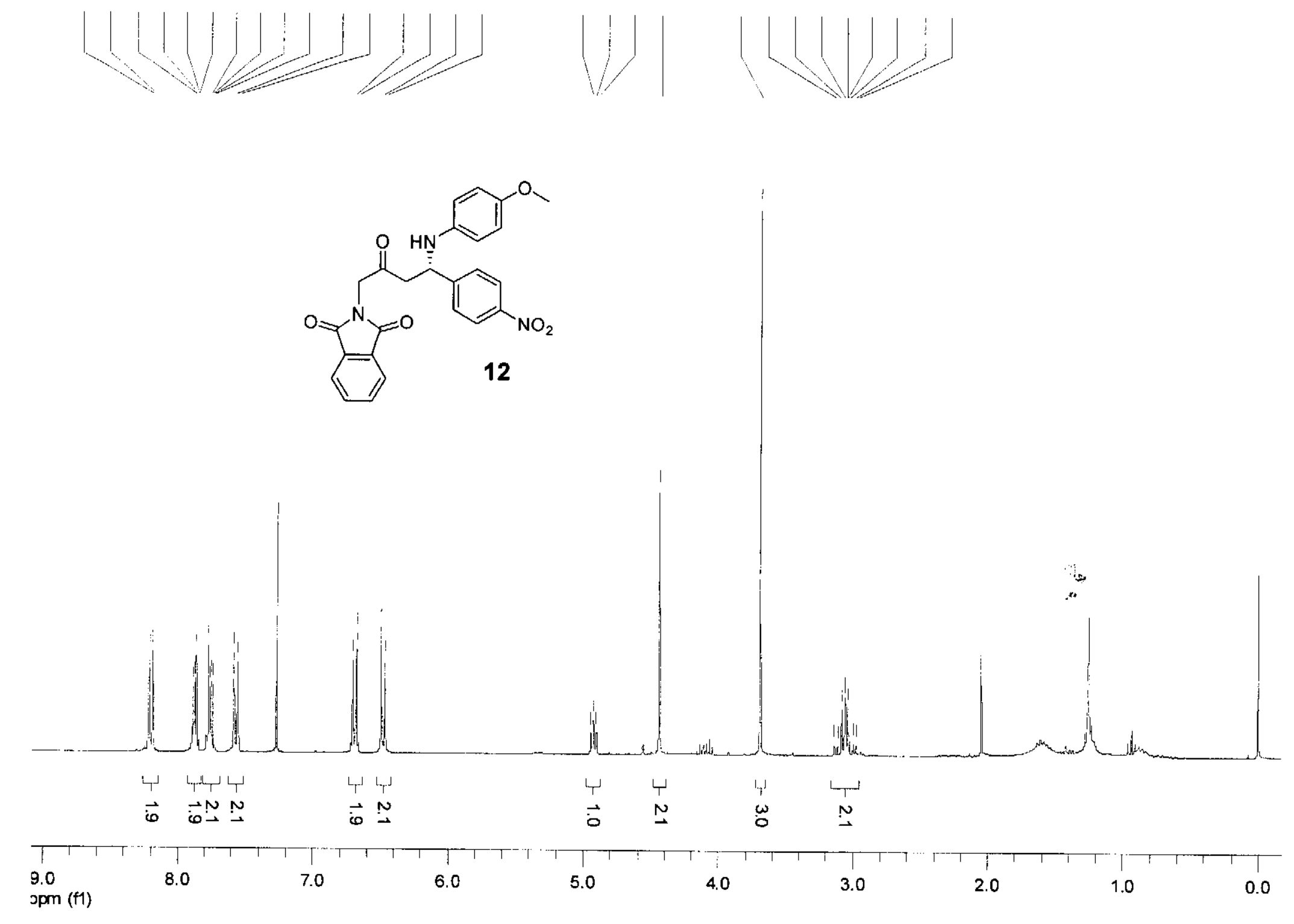




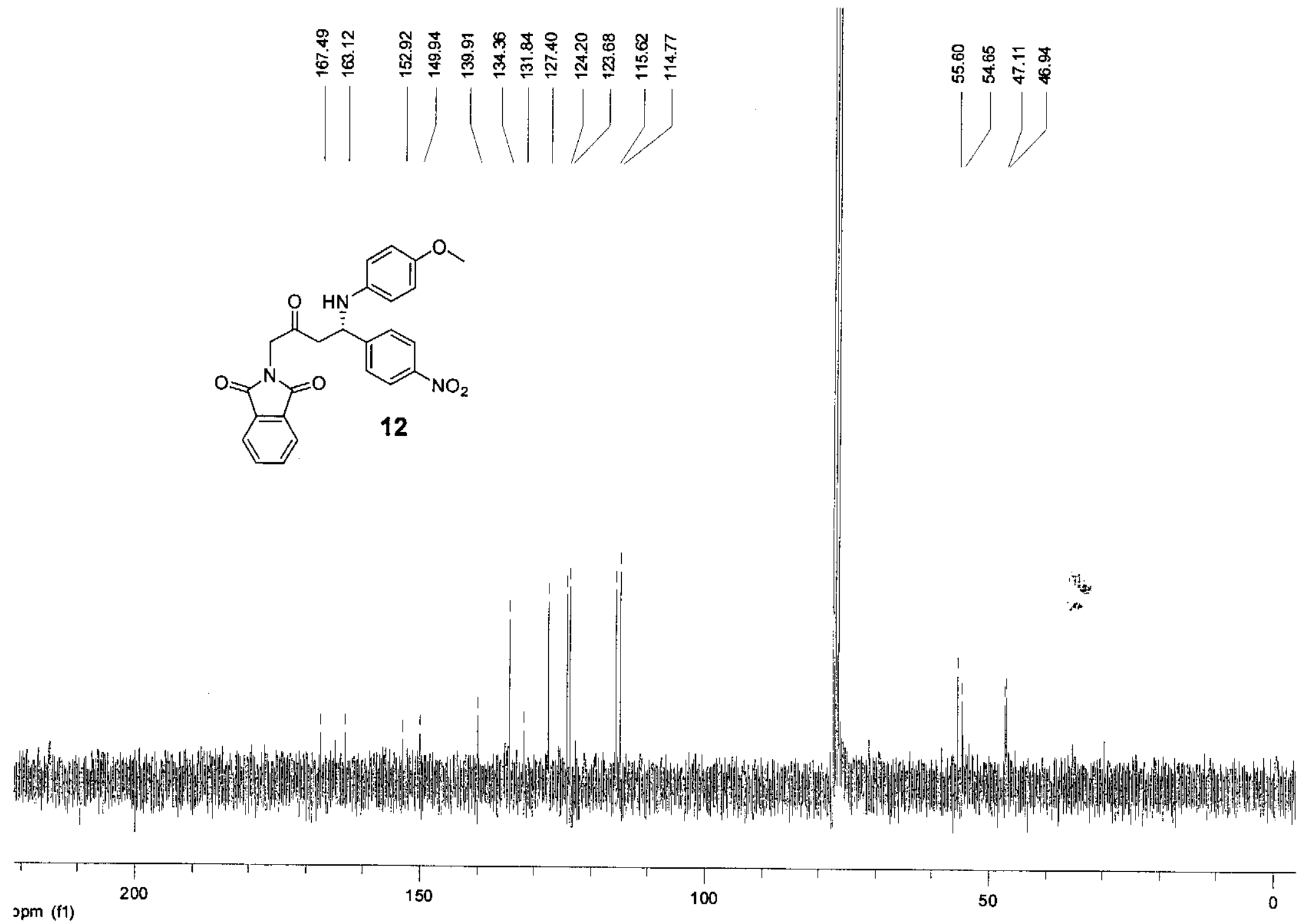



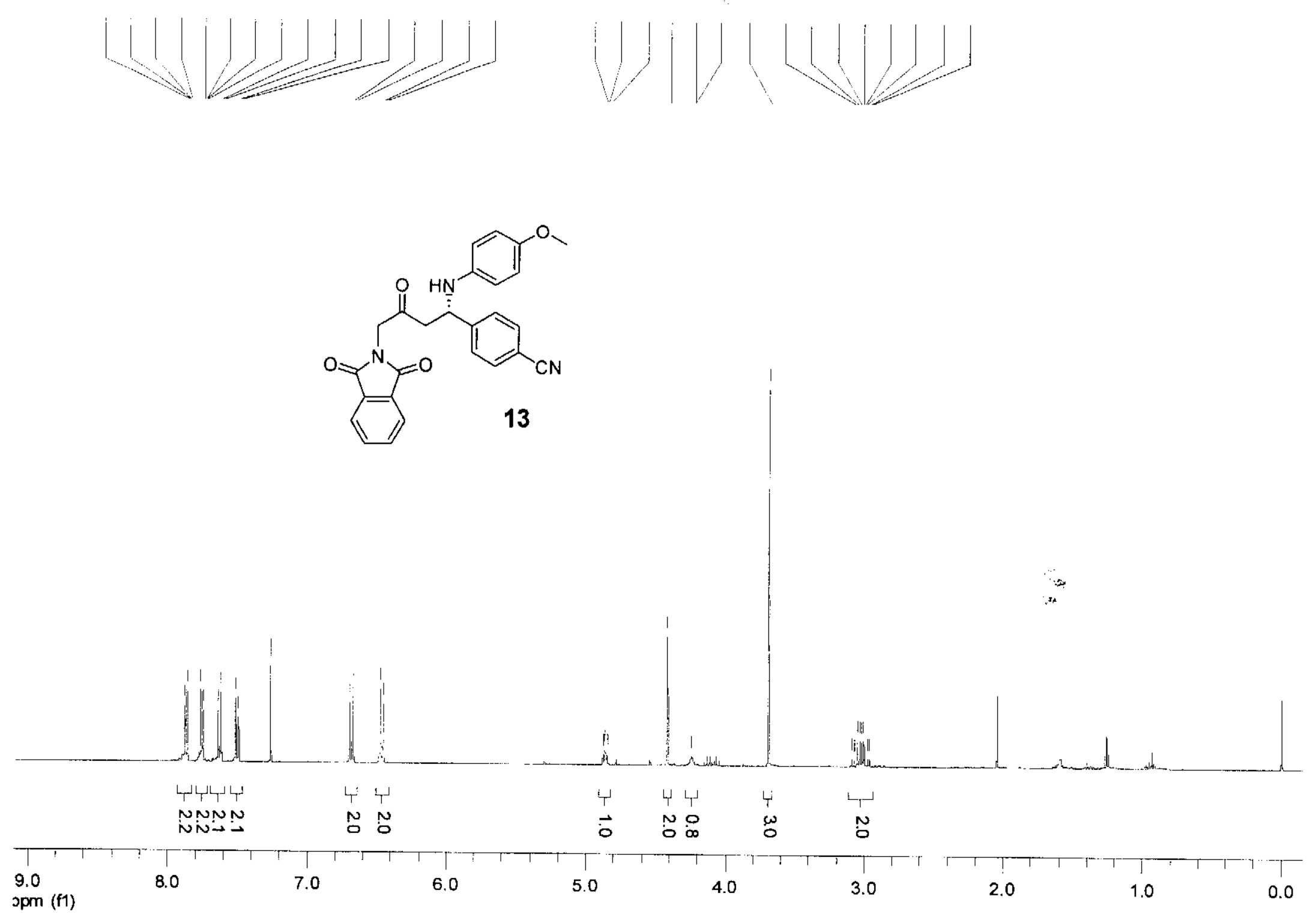


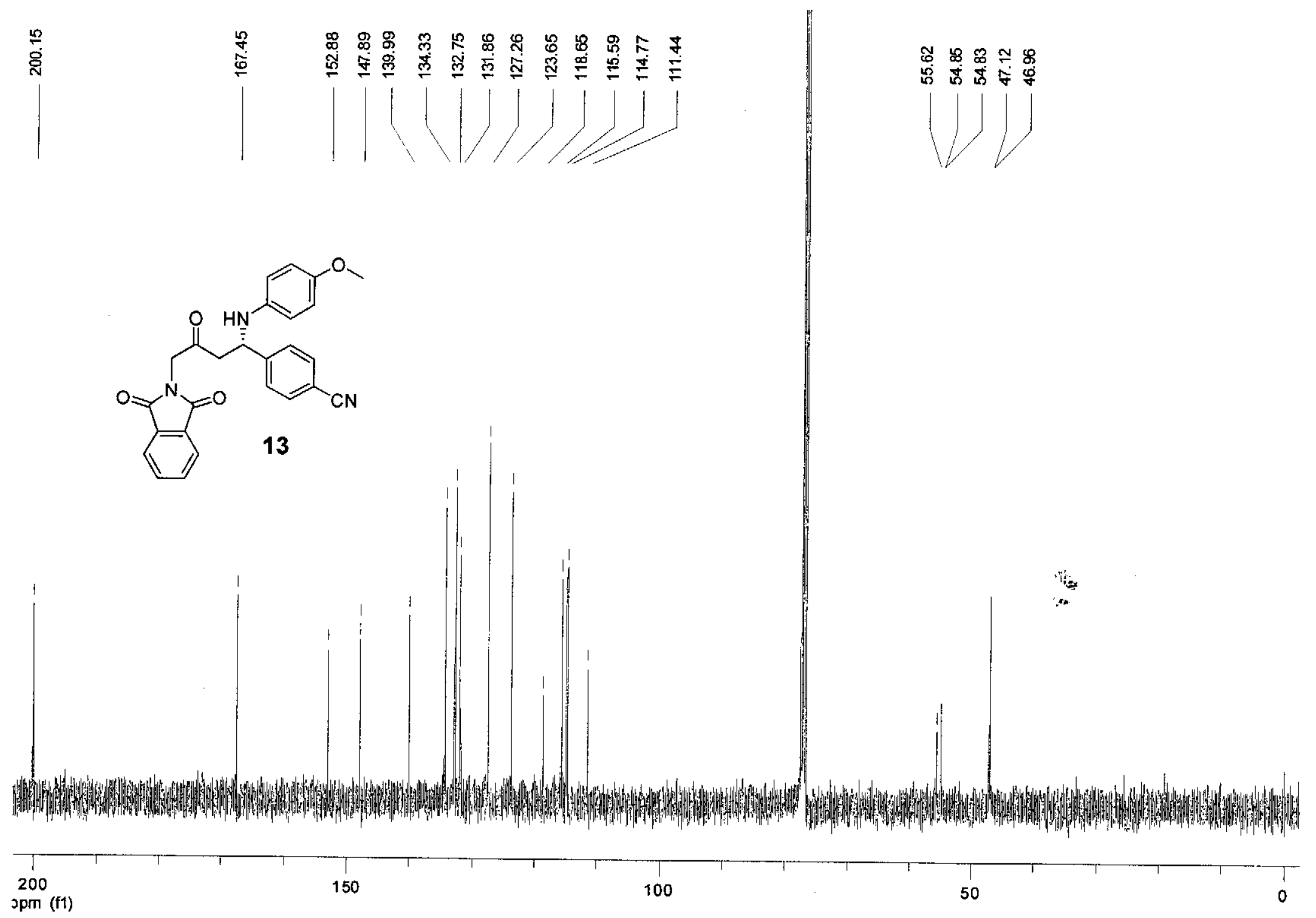




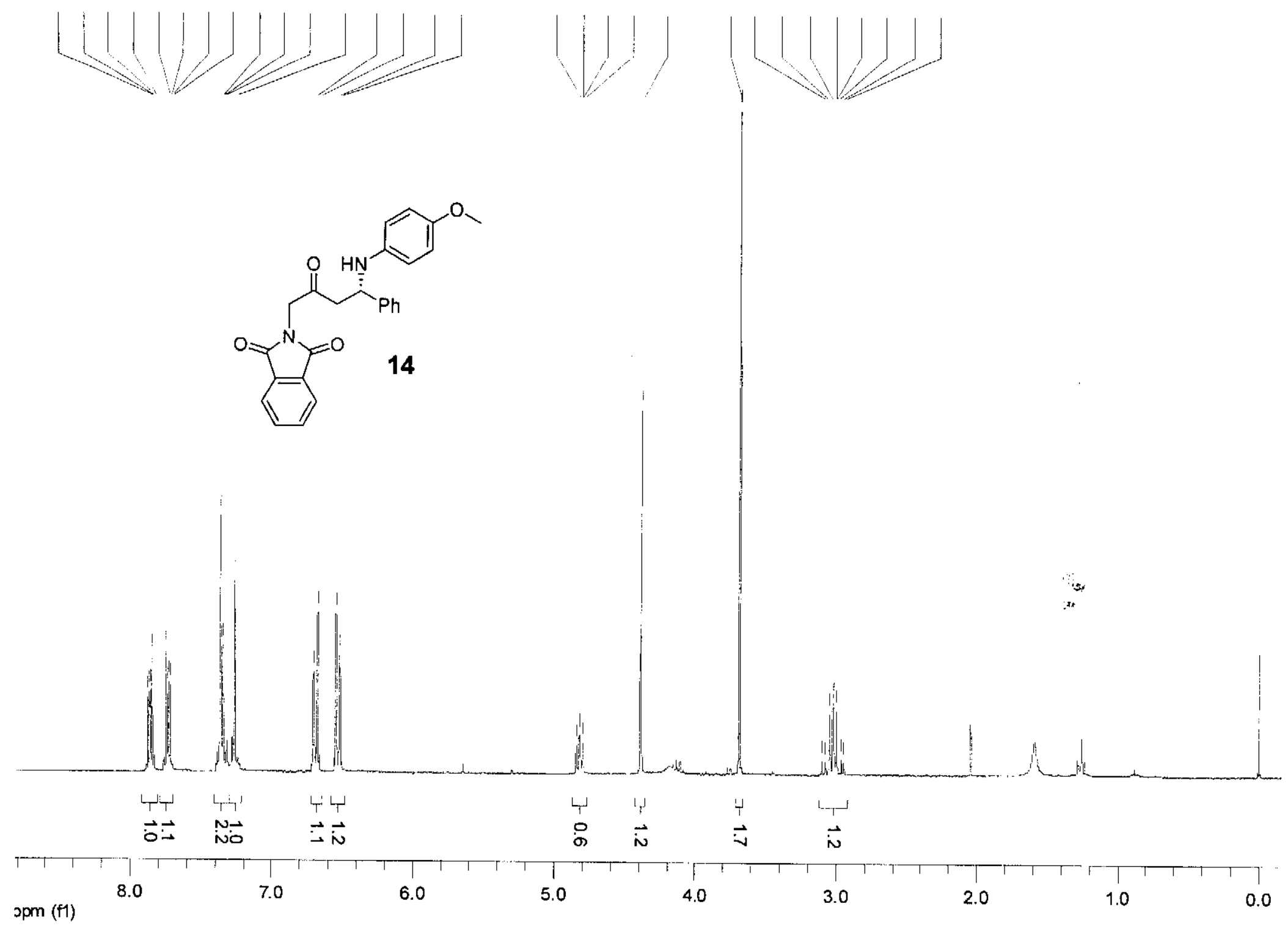




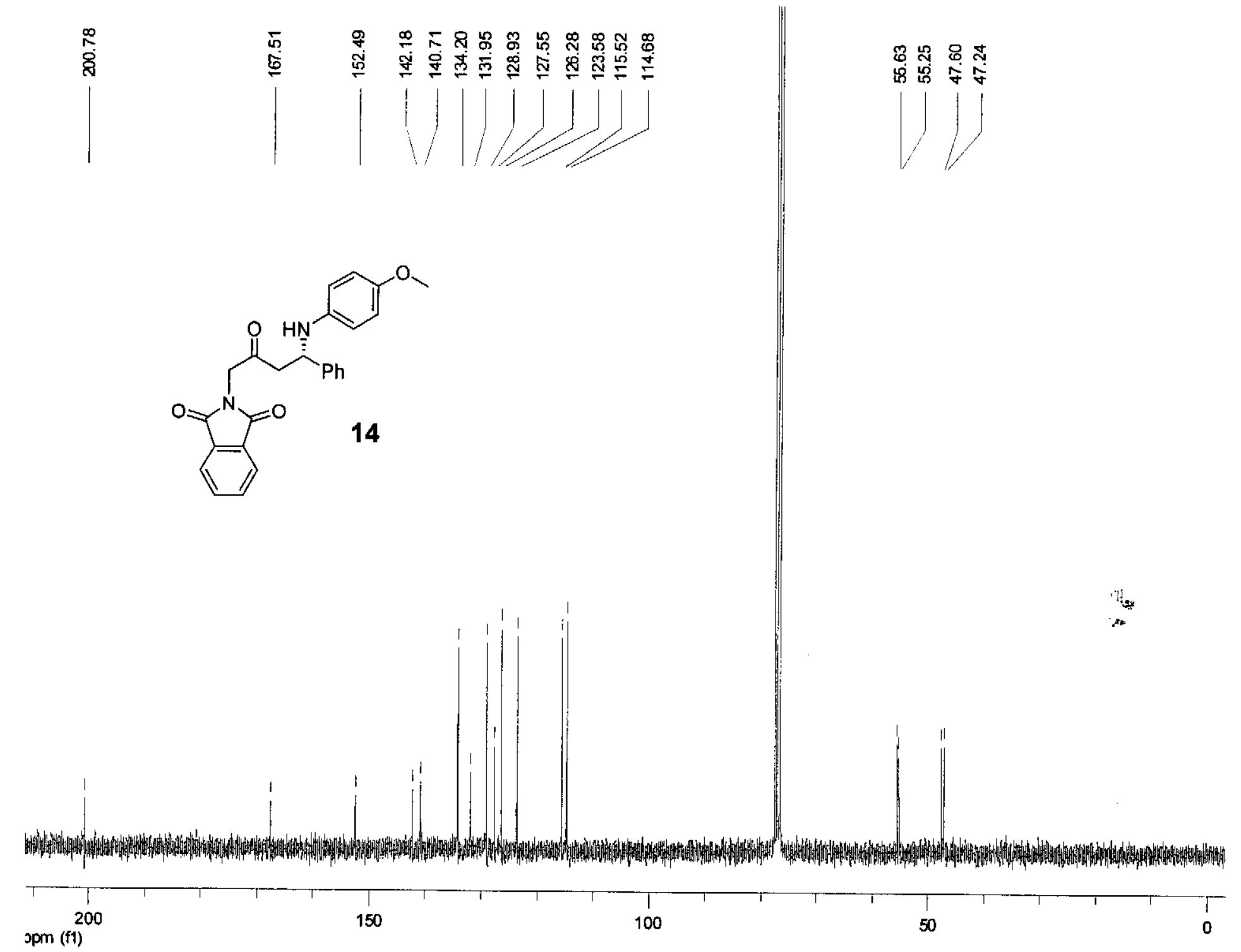




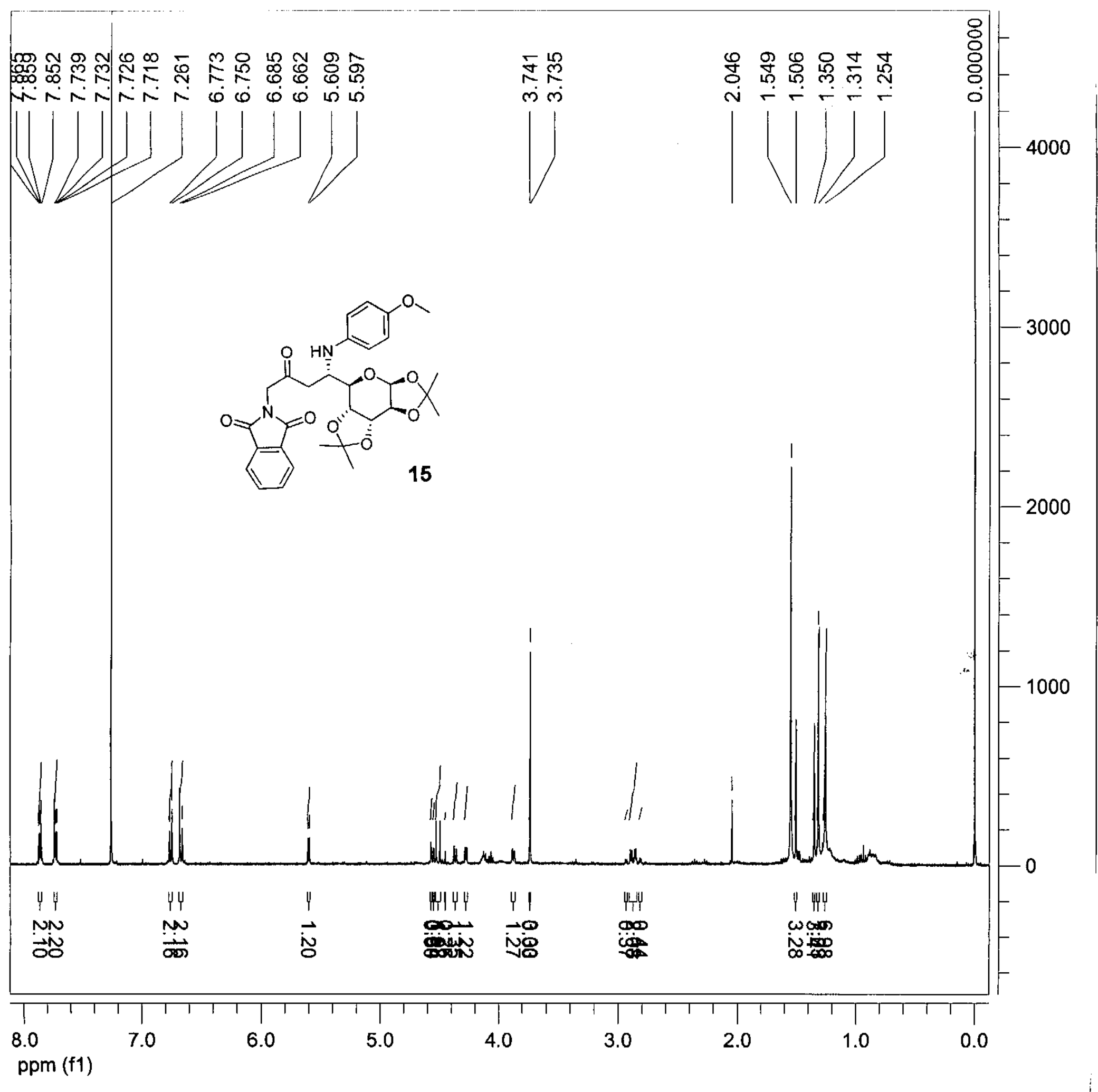




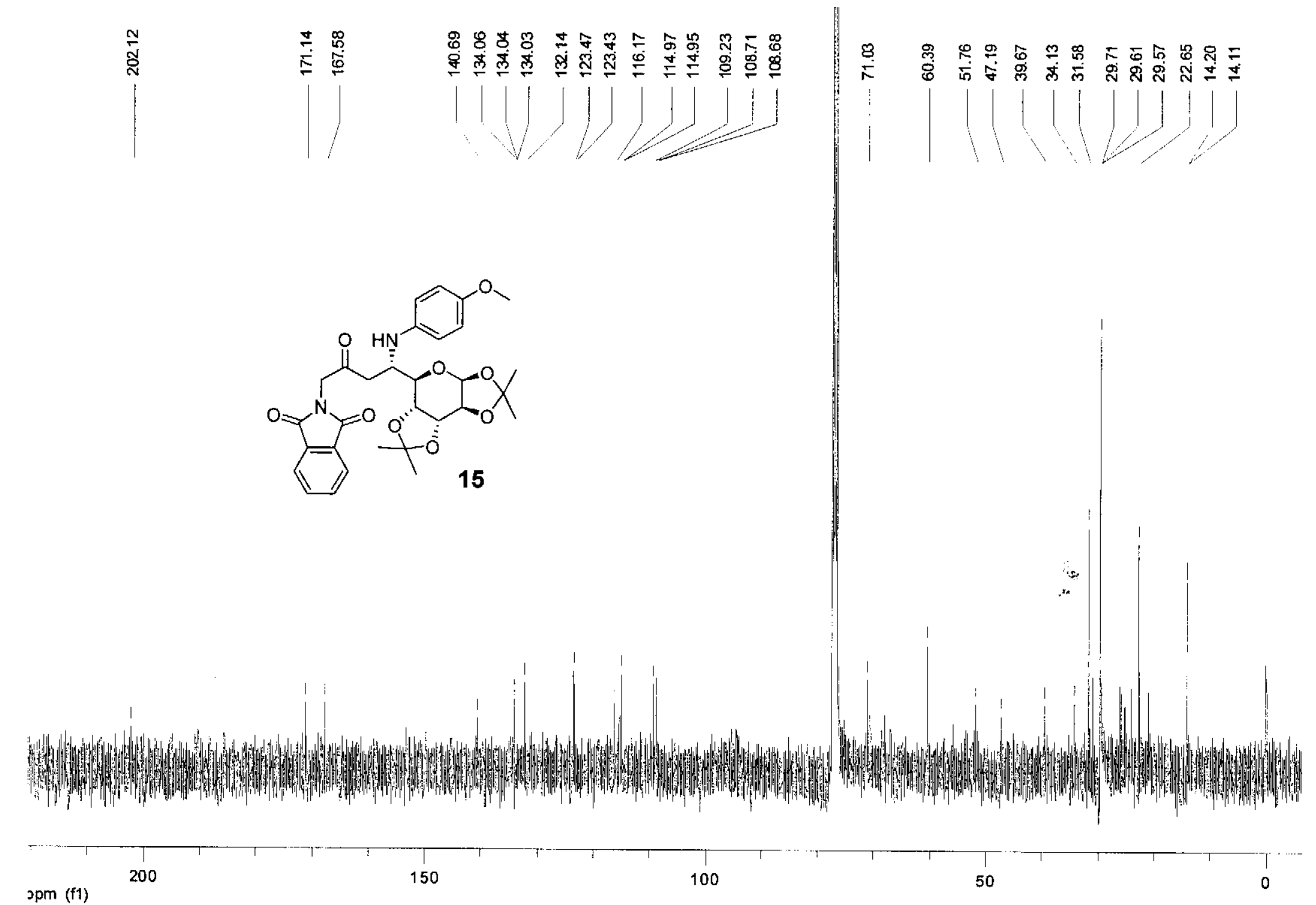




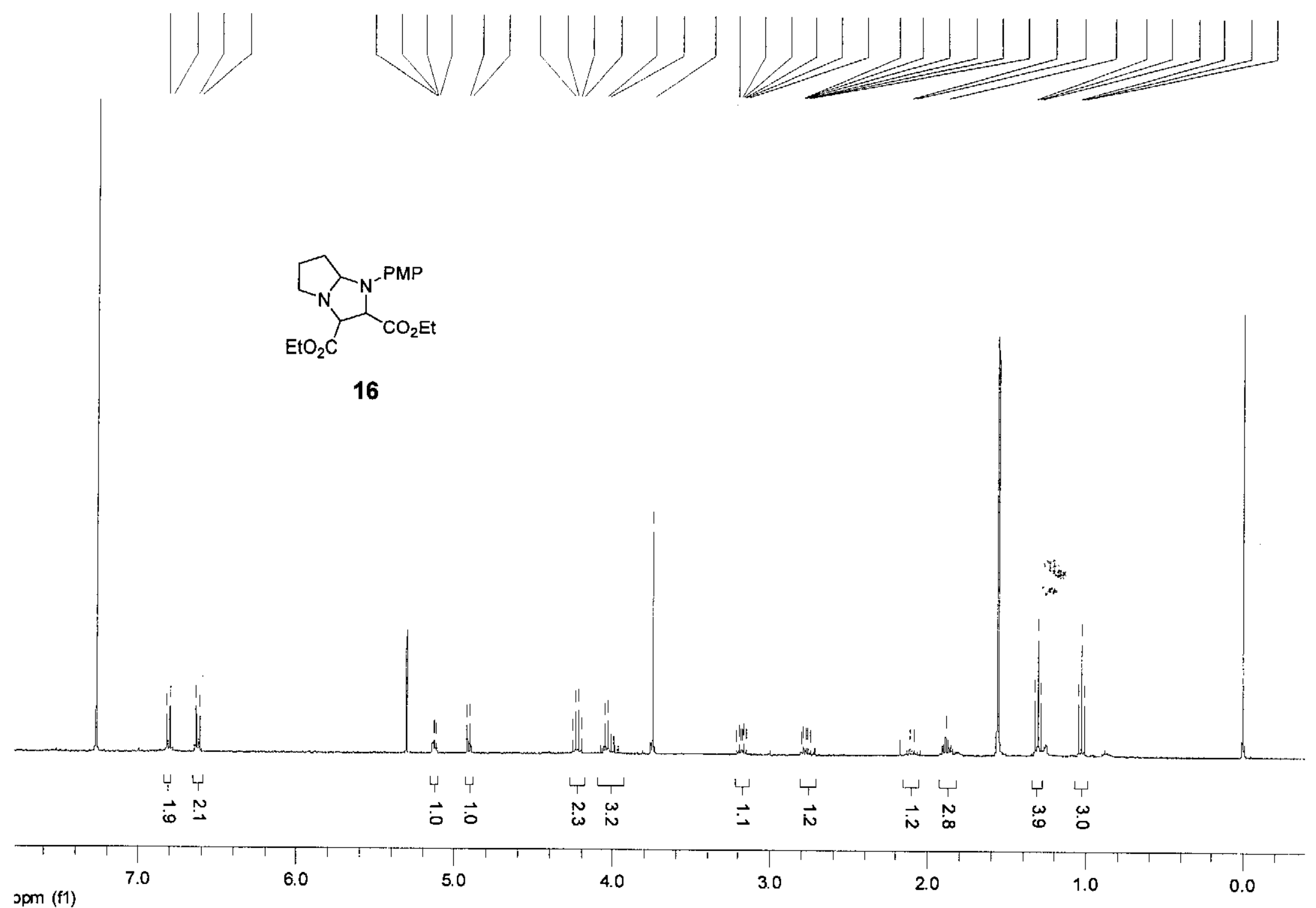

